\title{
Three dimensional porous scaffolds derived from collagen, elastin and fibrin proteins orchestrate adipose tissue regeneration
}

Journal of Tissue Engineering Volume 12: $1-17$ (C) The Author(s) 2021 Article reuse guidelines: sagepub.com/journals-permissions DOI: $10.1177 / 20417314211019238$ journals.sagepub.com/home/tej

(S)AGE

\author{
Prasad Sawadkar ${ }^{1,2,3}$ (D, Nandin Mandakhbayar ${ }^{4,5,6}$, \\ Kapil D Patel ${ }^{3,4,5,7}$, Jennifer Olmas Buitrago ${ }^{3,4,5}$, Tae Hyun Kim ${ }^{4,5,8}$, \\ Poojitha Rajasekar', Ferdinand Lali, ${ }^{2}$, Christos Kyriakidis', \\ Benyamin Rahmani '", Jeviya Mohanakrishnan', Rishbha Dua', \\ Karin Greco ${ }^{2,10}$, Jung-Hwan Lee Le,5,6 iD, Hae-Won Kim $^{3,4,5,6}$ iD, \\ Jonathan Knowles ${ }^{3,4,5,6,7}$ (iD) and Elena García - Gareta ${ }^{1,7}$
}

\begin{abstract}
Current gold standard to treat soft tissue injuries caused by trauma and pathological condition are autografts and off the shelf fillers, but they have inherent weaknesses like donor site morbidity, immuno-compatibility and graft failure. To overcome these limitations, tissue-engineered polymers are seeded with stem cells to improve the potential to restore tissue function. However, their interaction with native tissue is poorly understood so far. To study these interactions and improve outcomes, we have fabricated scaffolds from natural polymers (collagen, fibrin and elastin) by custom-designed processes and their material properties such as surface morphology, swelling, wettability and chemical cross-linking ability were characterised. By using 3D scaffolds, we comprehensive assessed survival, proliferation and phenotype of adipose-derived stem cells in vitro. In vivo, scaffolds were seeded with adipose-derived stem cells and implanted in a rodent model, with X-ray microtomography, histology and immunohistochemistry as read-outs. Collagenbased materials showed higher cell adhesion and proliferation in vitro as well as higher adipogenic properties in vivo. In contrast, fibrin demonstrated poor cellular and adipogenesis properties but higher angiogenesis. Elastin formed the most porous scaffold, with cells displaying a non-aggregated morphology in vitro while in vivo elastin was the most degraded scaffold. These findings of how polymers present in the natural polymers mimicking ECM and seeded with stem cells affect adipogenesis in vitro and in vivo can open avenues to design 3D grafts for soft tissue repair.
\end{abstract}

\section{Keywords}

Natural polymers, biomaterials, 3D porous scaffolds, tissue regeneration, tissue engineering

Received: 4 March 202I; accepted: 4 May 202I

\footnotetext{
'Regenerative Biomaterials Group, The RAFT Institute and The Griffin Institute, Northwick Park \& Saint Mark's Hospital, London, UK

${ }^{2}$ Division of Surgery and Interventional Science, University College London, London, UK

${ }^{3}$ UCL Eastman-Korea Dental Medicine Innovation Centre, Dankook University, Cheonan, Republic of Korea

${ }^{4}$ Institute of Tissue Regeneration Engineering (ITREN), Dankook

University, Cheonan, Republic of Korea

${ }^{5}$ Department of Nanobiomedical Science \& BK2I Plus NBM Global Research Centre for Regenerative Medicine, Dankook University, Cheonan, Republic of Korea

${ }^{6}$ Department of Biomaterials Science, School of Dentistry, Dankook University, Cheonan, Republic of Korea
}

\footnotetext{
${ }^{7}$ Division of Biomaterials and Tissue Engineering, UCL Eastman Dental Institute, University College London, London, UK

${ }^{8}$ R\&D Center, TE Bios Co, Osong, Republic of Korea

${ }^{9}$ Division of Respiratory Medicine, University of Nottingham,

Nottingham, UK

${ }^{10}$ The Griffin Institute, Northwick Park and St Mark's Hospital, London, UK

"Department of Mechanical Engineering, University College London, London, UK
}

Corresponding author:

Prasad Sawadkar, The RAFT Institute and The Griffin Institute,

Northwick Park \& Saint Mark's Hospital, London HAI 3UJ, UK.

Email: prasad.sawadkar@ucl.ac.uk 


\section{Introduction}

Adipose tissue plays a vital role in providing insulation, cushioning and aesthetics to the body. When its functions are compromised due to trauma, congenital defects, surgical resection, diseases and injury leading to decreased quality of life and morbidity, it necessitates surgical intervention to facilitate their repair and regeneration. ${ }^{1,2}$ Pioneering work into adipose tissue regeneration commenced in 1893 with the development of autologous fat transfer as a concept of tissue regeneration. ${ }^{3}$ Current gold standards for adipose tissue grafting are autografts and implant-based strategies, but they have inherent limitations such as donor site morbidity, shortage and immuno-compatibility.

To overcome these limitations, tissue engineering concepts have been developed over the last three decades whereby scaffolds fabricated from polymers and either seeded with cells or without having the potential to restore functional adipose tissue. Scaffold based strategies enhance physical and biological support until the formation of the neo-tissue, and they play a critical role in cell proliferation, differentiation and attachment. Additionally, scaffolds provide a microenvironment for tissue repair and regeneration. An ideal tissue-engineered scaffold should be biocompatible, expedite cell attachment and proliferation, elicit marginal immune reaction for release of cytokines and growth factors, and the mechanics of the scaffold should respond to the kinetics of the host tissue. An implanted scaffold should eventually be replaced by a host extracellular matrix (ECM) niche without causing toxicity to the surrounding tissue during the degradation process. $^{2}$

An off-the-shelf tissue-engineered scaffold can be fabricated from synthetic or natural polymers. The use of natural polymers such as collagen, elastin and fibrin, which are naturally found in the ECM, is advantageous. ${ }^{4}$ However, due to a limited understanding of the behaviour and interaction of those polymers with cells and natural ECM components as well as their capabilities to restore the functionality of tissue and organs, their clinical translation is still very restricted. ${ }^{5-7}$

Collagen is generally acknowledged as an advantageous biomaterial because of its homology across species, which provides low antigenicity and high biocompatibility. Collagen is the most abundant structural protein in the connective tissues accounting for $20 \%-30 \%$ of the total protein content in mammals. ${ }^{8-11}$ In humans, collagen represents one-third of the total protein content in the body. Elastin is an insoluble polymer with a half-life of 70 years. It acts as a dynamic modulator to enhance physiological function in large arteries, lung, ligament, tendon, skin and elastic cartilage. ${ }^{10,12,13}$ Fibrinogen is a freely circulating glycoprotein synthesised by the liver and cleaved by thrombin to form a fibrin protofibrils $3 \mathrm{D}$ network during blood coagulation. It acts as an initial natural scaffold for tissue regeneration and plays a vital role in cell-matrix interaction, inflammation, cell migration and wound healing. ${ }^{4,14,15}$ The properties displayed by these natural polymers present in the ECM can impute its use also in adipose tissue engineering applications.

In tissue engineering, structural properties of materials such as porosity, pore structure, pore thickness and mechanical properties are crucial for understanding integration, vascularisation and degradation of scaffolds, and this relationship is poorly understood so far. ${ }^{2,16}$ In our opinion, this is due to limitations in the literature regarding scaffolds structural properties studies, which are generally measured either on dry scaffolds or on those synthesised with definite pore properties that can differ considerably when scaffolds are hydrated, that is, after implantation. Secondly, there is no benchmark as such for measuring the architectural properties of biomaterials.

There is a major controversy in the literature in general regarding the properties of seeded versus bear scaffolds, and specifically, in our case, we aim to address here whether the use of stem cells is crucial for adipose tissue regeneration or not. Adipose tissue is anatomically located subcutaneously and in visceral planes. It is classified as a loose connective tissue consisting of a heterogeneous cell population of mesenchymal progenitor/stem cells, pericytes, $\mathrm{T}$ cells, macrophages, adipocytes, preadipocytes, endothelial cells and fibroblasts. ${ }^{17}$ Adipose tissue is easily accessible by lipo-aspiration or fat excision and stem cells from adipose tissue can yield cell numbers in the range of $3.5 \times 10^{5}-$ $1 \times 10^{6}$ from $1 \mathrm{~g}$ of aspirated fat, which is significantly higher than from $1 \mathrm{~g}$ of aspirated bone marrow that yields approximately $5 \times 10^{2}-5 \times 10^{5}$ cells. ${ }^{18-20}$ This abundance of the stem cell population, easy accessibility and higher potential to differentiate into various cell lineages such as adipogenic, osteogenic, chondrogenic, myogenic, etc. has captivated researchers to the use of adipose-derived stem cells in tissue engineering applications. ${ }^{21}$

The aim of our study was to investigate how different 3D environments made of proteins found in the natural 3D ECM affect adipose tissue regeneration with or without adipose-derived stem cells as a preliminary step to designing 3D biomimetic implants for adipose tissue regeneration.

\section{Methods and materials}

\section{Collagen, elastin and fibrin scaffolds fabrication}

Collagen hydrogel was fabricated by using $90 \%$ rat tail collagen type I $(2.16 \mathrm{mg} / \mathrm{ml}$ in $0.6 \%$ acetic acid) (First Link, Birmingham, UK) and $10 \%$ of $10 \mathrm{X}$ Minimal Essential Medium (Invitrogen, Paisley, UK). This solution was neutralised using $5 \mathrm{M}$ and $1 \mathrm{M}$ sodium hydroxide. Elastin scaffold was fabricated from $10 \%(\mathrm{v} / \mathrm{v})$ elastin 


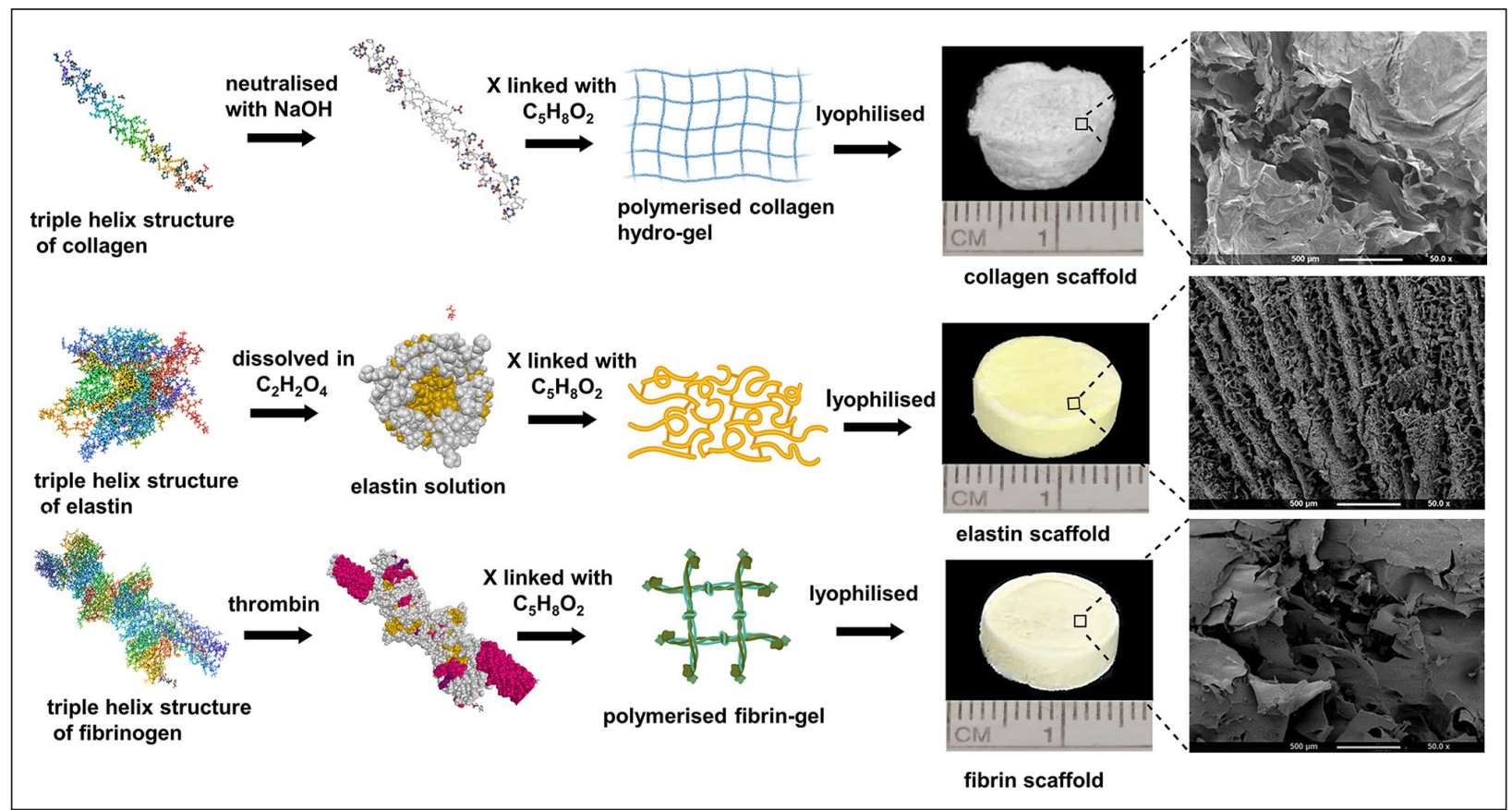

Figure I. Schematic representation of the fabrication of collagen, elastin and fibrin scaffolds with SEM structure of scaffolds at $50 \times$.

powder (Sigma, UK) that was mixed with $1 \mathrm{ml}$ of $0.5 \mathrm{M}$ oxalic acid (freshly prepared) at room temperature. Fibrin scaffold was fabricated by dissolving $2 \%$ bovine fibrinogen (Sigma, UK) in $1 \mathrm{ml}$ of $1 \mathrm{X}$ Phosphate buffered saline (PBS) and 10\% bovine thrombin. All the scaffolds were chemically cross-linked using $3 \%$ glutaraldehyde as a homobifunctional cross-linker agent and lyophilised to form a disc-shaped scaffold of $13 \mathrm{~mm}$ (diameter) $\times 4 \mathrm{~mm}$ (thickness) in dimension (Figure 1).

\section{Swelling ratio}

A swelling ratio for all scaffolds was calculated using the following equation:

$$
\mathrm{SR}=\frac{\mathrm{M}_{\mathrm{w}}-\mathrm{M}_{\mathrm{d}}}{\mathrm{M}_{\mathrm{w}}} \times 100
$$

where $M_{d}$ is the dry mass and $M_{w}$ is the wet mass of the scaffold. ${ }^{22}$ The dry mass of the scaffold was measured at time 0 and wet mass was calculated by submersing the scaffold into $5 \mathrm{ml}$ of distilled water for $15 \mathrm{~min}$ at $37^{\circ} \mathrm{C}$ and $5 \% \mathrm{CO}_{2}$.

\section{Dynamic water contact angle (dWCA)}

To determine wettability of scaffold's surface by intermolecular interaction, a dWCA was calculated. An experimental set up was created by dispensing $30 \mu \mathrm{l}$ of distilled water droplet onto each scaffold and its absorption pattern was video recorded over a period. By taking screen shots at each time point the dWCA was calculated using the principle of Young's equation with ImageJ (1.8.0_112) software (NIH, US). ${ }^{23}$

\section{Surface architecture}

Scaffolds were washed in deionised water to remove excess salts and mounted on stubs followed by sputtercoating with a carbon coater. All images were obtained using a secondary electron detector in a Philips XL 30 Field Emission SEM, operated at $5 \mathrm{kV}$ with an average working distance of $10 \mathrm{~mm}$.

\section{Biaxial mechanical testing}

The mechanical test was set up based on in vivo biomechanical environment. Samples were immersed in a temperature-controlled $\mathrm{PBS}$ bath at $37^{\circ} \mathrm{C}$ and the specimen thickness of each sample was determined. Equi-biaxial tensile tests were performed in displacement control on a commercial system, BioTester (CellScale Biomaterials Testing, Canada) and $23 \mathrm{~N}$ load cells. A pre-conditioning of five cycles at $0.25 \mathrm{~Hz}$ was applied. The gripping system consists in a so-called BioRake placed on each side of the specimen; equally spaced hooks pierce each side of the sample.

\section{Fourier-transform infrared spectroscopy (FTIR) and thermal gravimetric analysis (TGA)}

The surface chemistry and thermal behaviour of scaffolds (before and after cross-linking) were characterised by 
Table I. Forward and reverse primer.

\begin{tabular}{|c|c|c|c|}
\hline Name of gene & Forward primer & Reverse primer & Accession number \\
\hline MYODI & CGCCTGAGCAAAGTAAATGAG & GCCCTCGATATAGCGGATG & NM_002478 \\
\hline PPARG & GAATAAAGATGGGGTTCTCATATCC & AACTTCAGCAAACTCAAACTT & NM_I387| I \\
\hline CEBPA & CGGCAACTCTAGTATTTAGGATAAC & CAAATAAAATGACAAGGCACGATT & NM_004364 \\
\hline RUNX2 & TTCTССССТTTTСССАСТGA & CAAACGCAATCACTATCTATACСАТ & NM_004348 \\
\hline sox9 & GGACCAGTACCCGCACTTG & AATCCGGGTGGTCCTTCTTG & NM_000346 \\
\hline OCT4 & CACTAAGGAAGGAATTGGGAACA & GGGATTAAAATCAAGAGCATCATTG & NM_00270I \\
\hline REXI & CGTTTCGTGTCCCTTTCA & ССTCTTGTTCATTCTTGTTCGTATT & NM_I 74900 \\
\hline
\end{tabular}

attenuated total reflectance Fourier transformed infrared spectroscopy (ATR-FTIR, Varian 640-IR, Australia) and thermogravimetric analysis (TGA; N-1500; Scinco, South Korea). The TGA was carried out using a small portion of the scaffolds under nitrogen gas operation at temperature up to $800^{\circ} \mathrm{C}$ with heating rate of $10^{\circ} \mathrm{C} / \mathrm{min}$.

\section{Invitro hADSC seeding}

To study biological activity of the scaffolds, human adipose-derived stem cells (hADSCs) were commercially purchased (ATCC,UK) and cultured in MesenPRO RSTM basal cell culture medium (ThermoFisher, UK) supplemented with 2\% MesenPRO RSTM growth supplement (ThermoFisher, UK) and $1 \%$ penicillin/streptomycin (Sigma-Aldrich, UK) at $37^{\circ} \mathrm{C}$ with $5 \% \mathrm{CO}_{2}$. All the in vitro cell based experiments were carried out at passages three or four and scaffolds were seeded with $7.5 \times 10^{5}$ cells.

\section{Cell viability and proliferation}

To study cell viability and proliferation fabricated $3 \mathrm{D}$ porous scaffolds were seeded with 750,000 cells per scaffold. Cell viability of hADSC was investigated by a double staining kit (Invitrogen, UK). An assay solution was prepared by adding $0.2 \%(\mathrm{~V} / \mathrm{V})$ calcein-AM and $0.1 \%(\mathrm{~V} / \mathrm{V})$ propidium iodide (PI) in PBS. This solution was added to the scaffold and incubated at $37^{\circ} \mathrm{C}$ with $5 \% \quad \mathrm{CO}_{2}$ for $30 \mathrm{~min}$. Live and dead cells were visualised by fluorescence imaging and confocal microscopy (Leica DM IRE2 confocal microscope). To measure the quantitative rate of cell proliferation on scaffolds a resazurin-based AlamarBlue $^{\circledR}$ (BIO-RAD, UK) assay was used. An assay solution of 1:10 ( $\mathrm{vol} / \mathrm{vol})$ AlamarBlue was prepared in culture media and added to the cells and incubated at $37^{\circ} \mathrm{C}$ with $5 \% \mathrm{CO}_{2}$ for $3 \mathrm{~h}$. Absorbance was measured at 570 and $600 \mathrm{~nm}$ as reference wavelengths by using double beam UV/visible spectrophotometer (Spectronic Camspec Ltd, Garforth, UK).

\section{hADSC differentiation study}

A TRIzol (Invitrogen, Paisley, UK) based method was used to isolate RNA from the cells for 3, 7 and 14days according to manufactures instructions, and the yield was quantified by spectrophotometry (Spectronic Camspec Ltd, Garforth, UK), followed by cDNA synthesis using the Precision nanoscript 2 reverse transcription kit (Primer Design, Southampton, UK). A quantitative PCR was performed with custom designed and synthesised primers (Table 1) (Primer design, Southampton, UK) for analysis of differentiation pathways of hADSC.

\section{Isolation, identification and culture of rADSC}

To seed scaffolds with rat adipose-derived stem cell (rADSC), three female rats were euthanised and white adipose tissue (WAT) was isolated from inguinal, anterior and retroperitoneal fat pads. A standard ADSC isolation protocol was performed. Briefly, WAT was minced thoroughly with a sterile scalpel and digested with pre-warmed $0.2 \%$ collagenase I and $0.075 \%$ collagenase II in PBS for $2 \mathrm{~h}$ at $37^{\circ} \mathrm{C}$. Collagenases were inactivated by adding fetal bovine serum (FBS) and centrifuged at $800 \times g$ for $10 \mathrm{~min}$ at room temperature. The cell pallet was re-suspended in Red blood lysis (RBC) lysis buffer $(1: 9, \mathrm{v}: \mathrm{v})$ and incubated for $10 \mathrm{~min}$ at room temperature, followed by centrifugation at $800 \times g$ for $10 \mathrm{~min}$ and re-suspended in $20 \mathrm{ml}$ of proliferation medium. This cell suspension was filtered through a $100 \mu \mathrm{m}$ nylon mesh cell strainer and cultured at $37^{\circ} \mathrm{C}$ and $5 \% \mathrm{CO}_{2}$ for $24 \mathrm{~h}$. After $24 \mathrm{~h}$ non-adherent cells were removed, and cells were passaged twice after reaching $70 \%$ confluence level. To identify pure rADSC population, cell surface markers staining was performed followed by flow cytometry using BD FACSARIA III (BD Biosciences, NJ, USA). Cell population tested positive for CD 105, CD 90, CD 73 and negative for CD 31, CD 34 (Supplemental Figure S3). Cultured rADSC's differentiation potential was tested for adipogenic, osteogenic and chondrogenic lineages using Oil Red O, ALP staining and Alcian blue staining respectively (Supplemental Figure S4). In the cellular group, each scaffold was seeded with rADSC $\left(1 \times 10^{6}\right.$ cells $/$ scaffold $)$ and incubated at $37^{\circ} \mathrm{C}$ with $5 \% \mathrm{CO}_{2}$ for $4 \mathrm{~h}$ to allow cell attachment.

In vivo implantation. The animal husbandry and experimental protocols were approved by the Animal Care and Use Committee at Dankook University, Republic of Korea. In this experiment 9 Sprague-Dawley 9-10 weeks 
old (170-210g), healthy male rats were used, and the study was divided into two groups acellular (scaffold) and cellular group (scaffold + rADSC). All surgeries were performed under general anaesthesia of an intramuscular injection of a mixture of ketamine $(80 \mathrm{mg} / \mathrm{kg})$ and xylazine $(10 \mathrm{mg} / \mathrm{kg})$. The dorsal region was shaved and disinfected with iodine solution and an incision of $2 \mathrm{~cm}$ was made in the dorsal-medial region. Scaffolds types were randomised and implanted in each side of the anterior and posterior region within intercostal space (four scaffolds per animal). At the end of the study period (after 28 days), rats were anaesthetised under the isoflurane and $420 \mathrm{mg} / \mathrm{kg}$ Ioversol (Optiray $350 \mathrm{Rx}$, Guerbet LLC, USA) an iodine-based compound was injected into the left ventricle to visualise blood vessels into the scaffold. After $15 \mathrm{~min}$ rats were euthanised by $\mathrm{CO}_{2}$ inhalation. Scaffolds with the surrounding tissue were harvested and fixed in $10 \%$ neutral buffered formalin for $2 \mathrm{~h}$ at room temperature.

X-Ray micro-computed tomography. Pre and post implanted scaffolds were wrapped in a transparent plastic film and mounted for scanning using submicron resolution $\mu \mathrm{CT}$ (Skyscan 1176, Skyscan, Belgium) and scan was performed with the settings: $45 \mathrm{kV}$ X-ray voltage, $0.2 \mathrm{~mm}$ aluminium filter, source current $556 \mu \mathrm{A}, 0.5^{\circ}$ rotation step, exposure time of $180 \mathrm{~ms}$ for each section. Three-dimensional (3D) models were reconstructed using Skyscan NRecon software (Bruker micro-CT, Belgium) and reconstructed dataset was processed after segmentation and binarisation to analyse pore size, pore thickness, porosity $\%$ by CTAn software (Bruker micro-CT, Belgium), angiogenesis by CTVol software (Bruker micro-CT, Belgium) and volume degradation by Drishti software (ANU, Australia).

Histological analysis. Post micro CT scanning, tissue sections were fixed in a $10 \%$ neutral buffered formalin and embedded in paraffin wax for the routine histology. To examine the cellularity, ECM structure and immune response to the scaffolds, $3 \mu \mathrm{m}$ sections were de-waxed and stained with H\&E, collagen-based scaffolds were additionally stained with Sirius Red and fibrin scaffolds with Martius Scarlet and Blue (MSB) while elastin scaffolds were stained with Verhoeff-Van Gieson stain (VVG).

Immunofluorescence microscopy. Primary antibodies DLK-1 (ab89908) and FABP4 (ab92501) were from Abcam (UK), PPAR $\gamma$ (sc-7273) was from Santa Cruz (UK) and Caveolin-1 3267 was from Cell Signalling Technology (UK). Secondary antibodies Goat anti-rabbit IgG DyLight 549 and Horse anti-mouse, IgG DyLight 488 were from Vector Laboratories (Peterborough, UK). Immunostaining was performed using standard protocol, in short, a section of $5 \mu \mathrm{m}$ was de-waxed for each scaffold and antigen retrieval was carried out by citrate acid-based antigen unmasking solution (Vector Laboratories, Peterborough, UK). Sections were subsequently blocked in $2.5 \%$ normal goat serum (Vector Laboratories, Peterborough, UK) for $1 \mathrm{~h}$ before incubating in primary antibodies diluted at 1:200 and incubated overnight at $4^{\circ} \mathrm{C}$. The secondary antibody, Goat anti-rabbit IgG DyLight 549 was used to detect DLK1, FABP4 and Caveolin-1 whilst Horse anti-mouse IgG DyLight 488 was used to detect PPAR $\gamma$. Secondary antibodies were used at 1:200 dilution and incubated for $2 \mathrm{~h}$ at room temperature. All sections were washed at the end of the staining and mounted in Flouroshield ${ }^{\mathrm{TM}}$ (SigmaMerck, UK). Immuno-fluorescent images were captured using an Olympus IX-71 inverted microscope using a 20X objective (0.3 nu-merical aperture).

Statistical analysis. All results presented in Mean \pm standards deviation. The significance of results was studied using 2-way analysis of variance (ANOVA) at $95 \%$ confidence interval with two tail alpha level 0.05, ( $p$-value) using GraphPad Prism 7.03 (GraphPad Software, Inc, CA, USA).

\section{Results and discussion}

\section{Physicochemical characterisation}

In this study, we have developed and tested methods for adipose tissue regeneration using natural polymers present in the human ECM. Surface topological differences were observed in all three types of scaffolds. The swelling ratio was an indication of the interaction between a physiological solvent (i.e. water) and scaffolds. When the scaffolds were submerged, they absorbed the solvent, causing them to swell. The calculated swelling ratio for collagen was $92.37 \% \pm 3.12 \%$, and for fibrin was $90.50 \% \pm 3.77 \%$. Elastin, however, showed the lowest ratio of $35.73 \% \pm 77 \%$. This indicates that the solvent absorbing capacity of elastin scaffolds was weaker than collagen and fibrin scaffolds (Figure 2(a)). This is because elastin scaffolds had a hydrophobic nature as calculated dynamic water contact angle (dWCA) for $0 \mathrm{~s}$ was $102^{\circ} \pm 7.75^{\circ}$. In material science, dWCA is the gradient that determines the wettability of the material. When a determined material shows dWCA $>90^{\circ}$ it is considered as hydrophobic, such as elastin because naturally, it is an insoluble and stable protein. ${ }^{24}$ Fibrin is hydrophobic, but its precursor fibrinogen is extremely hydrophilic; however, in our study, fibrin scaffold demonstrated dWCA of $66.18^{\circ} \pm 10.9^{\circ}$ which was an indication of a hydrophilic nature. We propose that this shift in the wettability was due to glutaraldehyde mediated cross-linking. ${ }^{25}$ Collagen scaffolds showed dWCA of $0^{\circ}$ at $0 \mathrm{~s}$ indicating 100\% hydrophilic nature of the scaffold (Figure 2(b)). This was due to chemical cross-linking of collagen with glutaraldehyde as chemically crosslinked collagen 


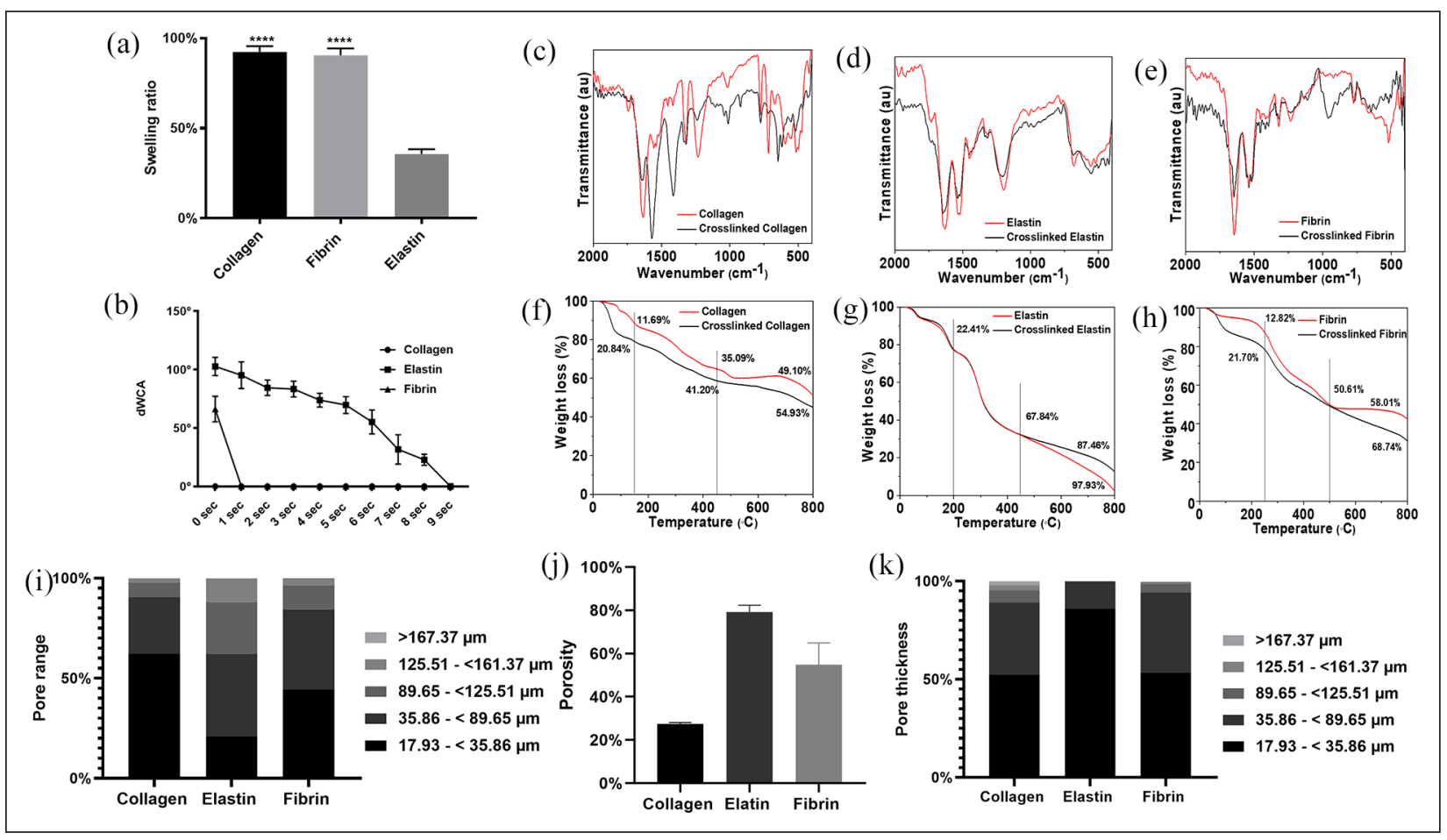

Figure 2. Swelling ratio of the scaffolds swelling ratio $(* * * * p<0.000$ I significance to elastin): (a) water contact angle (WCA), (b) Fourier-transform infrared spectroscopy (FTIR) for collagen, (c) elastin, (d) fibrin, (e) thermal gravimetric analysis (TGA) for collagen, (f) elastin, (g) fibrin, (h) pore properties of scaffolds measured using $\mu \mathrm{CT}$, pore range, (i) porosity, and (j) pore thickness (K).

scaffolds have increased wettability and perfusion of liquid. ${ }^{26}$ Procedures such as attenuated total reflection Fourier transform infrared spectroscopy (ATR-FTIR), and thermal gravimetric analysis (TGA) can be used to evaluate the effect of cross-linking on surface chemistry, protein structure and thermal behaviours of scaffolds. ATR-FTIR spectroscopy was used to observe the changes in the secondary structure of the scaffolds upon cross-linking with glutaraldehyde. Figure 2(c)-(e) shows the ATR-FTIR spectra of collagen, elastin, fibrin and glutaraldehyde crosslinked collagen, crosslinked elastin and crosslinked fibrin scaffolds, respectively. Figure 2(c) shows the ATRFTIR spectra of collagen before and after the cross-linking by glutaraldehyde. The ATR-FTIR spectrum of the collagen scaffold shows all the characteristic peaks at 1635.35, 1554.26 and $1231.35 \mathrm{~cm}^{-1}$ associated with amide I, amide II and amide II, respectively, which predominantly corresponds to the $\mathrm{C}=\mathrm{O}$ stretch vibration of amide $\mathrm{I}$, while the peak at $1554.26 \mathrm{~cm}^{-1}$ is associated with amide II and ascribed to the presence of N-H plane band and the C-H stretch vibration. ${ }^{27,28}$ The peaks at 1452.67 , and $1410.81 \mathrm{~cm}^{-1}$ are associated with asymmetric and symmetric $\mathrm{CH}_{3}$ bending vibrations. ${ }^{29}$ The peak at $1231.35 \mathrm{~cm}^{-1}$ is associated with amide III and arises from $\mathrm{C}-\mathrm{OH}$ stretching mode. After cross-linking with glutaraldehyde, the amide I peaks positions shifted to $1642.6 \mathrm{~cm}^{-1}$ and the reduced intensity indicates the conformational change in triple helix. ${ }^{30-32}$ The amide II peak position also shifted towards higher wavenumber from 1554.26 to $1571.78 \mathrm{~cm}^{-1}$ and increased intensity, indicating that amino $\left(-\mathrm{NH}_{2}\right)$ groups of the lysine residue of collagen react with aldehyde (-CHO) groups of glutaraldehyde to form the aldimine linkage $(\mathrm{CH}=\mathrm{N}){ }^{33}$ The peaks at $1452.67 \mathrm{~cm}^{-1}$ disappeared and $1410.18 \mathrm{~cm}^{-1}$ transformed into an intense peak suggesting an increase in symmetric $\mathrm{CH}_{3}$ bending vibration. Increased intensity of amide III was also observed after glutaraldehyde cross-linking. Additionally, peaks at $669.61,594.37$ and $495.52 \mathrm{~cm}^{-1}$ disappeared, and new peaks at 1043.24 , $920.79,646.01$ and $622.77 \mathrm{~cm}^{-1}$ were observed. The presence of new peaks and the disappearance of some old peaks confirmed the chemical interaction between collagen after the glutaraldehyde treatment. Figure 2(d) shows the ATR-FTIR spectra of elastin before and after the crosslinking with glutaraldehyde. The spectrum of the elastin scaffold shows characteristic peaks at $1632.28 \mathrm{~cm}^{-1}$ associated with amide $\mathrm{I}$ and originate from the $\mathrm{C}=\mathrm{O}$ stretching vibration of the elastin and peaks at 1544 and $1524.6 \mathrm{~cm}^{-1}$ attributed to $\mathrm{N}-\mathrm{C}=\mathrm{O}$ stretching vibrations of amide II. The peak at $1197.78 \mathrm{~cm}^{-1}$ is a sign of random coil conformation. ${ }^{34,35}$ The ATR-FTIR spectrum of crosslinked elastin scaffold showed similar peak intensity and positions except for amide I and amide II, which shifted towards higher wavenumber from 1632.28 to $1651.82 \mathrm{~cm}^{-1}$ and from 1197.78 to $1223.97 \mathrm{~cm}^{-1}$, respectively. This slight upshifts of the peaks are attributed to differences in the local environment of the functional groups and possible 
interaction with neighbouring atoms. Figure 2(e) shows the ATR-FTIR spectra of fibrin before and after the crosslinking with glutaraldehyde. The ATR-FTIR spectrum of the fibrin scaffold shows characteristic peaks at $1646.46 \mathrm{~cm}^{-1}$ associated with amide I and originates from the $\mathrm{C}=\mathrm{O}$ stretching vibration of the fibrin and peaks at 1537.85 , and $1522.36 \mathrm{~cm}^{-1}$ are attributed to $\mathrm{N}-\mathrm{C}=\mathrm{O}$ stretching vibrations and aromatic $\mathrm{C}-\mathrm{C}$ of the Thy of amide II, respectively. ${ }^{36}$ The peaks at 1321.7 and $1235.4 \mathrm{~cm}^{-1}$ correspond to amide III and arise from N-H bending and $\mathrm{C}-\mathrm{N}$ stretching, respectively. ${ }^{37}$ The FTIR of glutaraldehyde crosslinked fibrin scaffold showed similar peak positions of amide I, amide II and amide III. However, two new peaks at 1110.4 and $960.9 \mathrm{~cm}^{-1}$ appeared after crosslinking with glutaraldehyde. This indicates that glutaraldehyde cross-linking affected the main protein structure and changed the secondary structure.

The thermo-gravitational analysis (TGA) of collagen, elastin and fibrin scaffolds before and after cross-linking with glutaraldehyde are shown in Figure 2(f)-(h). The thermal degradation of collagen, elastin, crosslinked collagen and crosslinked elastin scaffolds (Figure 2(f)-(h)) underwent weight loss in three stages. However, the thermal degradation of the fibrin scaffold before and after cross-linking shows different patterns (Figure 2(h)). The thermal degradation of fibrin scaffolds involved a threestage; however, crosslinked fibrin scaffold shows only two-stage thermal degradation. The collagen scaffold showed an initial $11.69 \% \quad\left(20^{\circ} \mathrm{C}-150^{\circ} \mathrm{C}\right), \quad 23.4 \%$ $\left(150^{\circ} \mathrm{C}-450^{\circ} \mathrm{C}\right)$, and $14 \%\left(450^{\circ} \mathrm{C}-800^{\circ} \mathrm{C}\right)$ weight loss for stage I, II and III, respectively, which represents the evaporation of physiosorbed water molecules, thermal degradation of collagen fibrous structures, and carbonisation of residual organic components. Similarly, crosslinked collagen scaffolds also exhibited three-stage thermal degradation of $20.84 \%, 20.4 \%$ and $13.17 \%$ in the same temperature regions which represent the evaporation of physiosorbed water molecules, thermal degradation of collagen fibrous structures, and carbonisation of residual organic components (Figure 2(f)). The thermal degradation behaviours of collagen before and after cross-linking with glutaraldehyde do not show significant change. Moreover, the degradation pattern is similar except the initial significant drop in crosslinked scaffolds. The thermal degradation of elastin scaffolds before and after glutaraldehyde cross-linking also shows similar patterns (Figure 2(g)). The thermal degradation of elastin scaffolds involved three-stage degradation: $22.41 \%\left(20^{\circ} \mathrm{C}-200^{\circ} \mathrm{C}\right), 45.43 \%\left(200^{\circ} \mathrm{C}-450^{\circ} \mathrm{C}\right)$, and $30 \%\left(450^{\circ} \mathrm{C}-800^{\circ} \mathrm{C}\right)$ weight loss for stage I, II and III, respectively, which represents the evaporation of physiosorbed water molecules, major denaturation behaviour reported for native elastin, ${ }^{33,34}$ and effect of cross-linking and change in secondary structure. Finally, the thermal degradation of fibrin scaffolds before and after glutaraldehyde cross-linking shows different patterns (Figure 2(h)).
The thermal degradation of fibrin scaffolds involved three stage degradation: $12.82 \% \quad\left(20^{\circ} \mathrm{C}-250^{\circ} \mathrm{C}\right), \quad 37.73 \%$ $\left(250^{\circ} \mathrm{C}-500^{\circ} \mathrm{C}\right), 7.4 \%\left(500^{\circ} \mathrm{C}-800^{\circ} \mathrm{C}\right)$, weight loss for stage I, II and III, respectively, which represents the evaporation of physiosorbed water molecules, carbonisation of residual organic components such as $\mathrm{C}=\mathrm{O}, \mathrm{N}-\mathrm{C}=\mathrm{O}$, primary and secondary amide, and the burning of hydrocarbons, respectively. However, the crosslinked fibrin scaffolds showed only two-stage thermal degradation: $21.7 \%\left(20^{\circ} \mathrm{C}-250^{\circ} \mathrm{C}\right)$ and sustained degradation of $40 \%$ $\left(250^{\circ} \mathrm{C}-800^{\circ} \mathrm{C}\right)$ weight loss, respectively, which represents the evaporation of physiosorbed water molecules, corresponds to native degradation of carbons and other functional groups such as amides and carboxyl. Similar degradation trend was observed in vivo implanted crosslinked scaffolds

\section{X-ray microtomography of scaffolds}

In order to fabricate a functional tissue-engineered scaffold, the degradation of the implanted matrix should be synchronised with neo-tissue formation for cell migration and proliferation. ${ }^{2}$ Hence in vivo scaffold degradation and $3 \mathrm{D}$ volume was analysed and quantified by X-ray microtomography $(\mu \mathrm{CT})$ (Figure 3(a)). After 28 days the collagen scaffolds volume was decreased by $50.33 \pm 7.5$ for acellular scaffolds and $66.33 \pm 1.15$ for the cellular scaffolds. Interestingly, the \% reduction was higher in cellular scaffolds than acellular scaffolds, although the difference was marginal. In fibrin, there was $62.05 \% \pm 2.46 \%$ reduction on the acellular scaffolds and $50.03 \% \pm 8.21 \%$ in cellular scaffolds (Figure 3(b)). Elastin was the most degraded scaffold with $88.01 \% \pm 9.19 \%$ degradation in acellular scaffolds and $50.03 \% \pm 8.21 \%$ in cellular scaffolds. A primary reason for this was that elastin scaffolds were fabricated from an insoluble source, which did not form a strong fibril network and resulted in mechanically and structurally weaker scaffolds. ${ }^{38}$ Interestingly, the degradation of cellular collagen scaffolds was faster than acellular collagen scaffolds. This was due to mediated traction forces and contraction by seeded rADSC that leads to remodelling of the scaffold, and this phenomenon is commonly observed in fibroblasts seeded in a collagen scaffold, and MSC seeded in collagen hydrogel. ${ }^{39,40}$ In the fibrin groups, acellular scaffolds degraded faster than the cellular group, but overall, all scaffolds were remodelled due to cellular mechanobiology by 28 days in vivo.

In the biomaterials field, cell-material interaction and structural relationships are critical for tissue engineering outcomes, but they are poorly understood, for example, it was reported that $>500 \mu \mathrm{m}$ mean pore size is ideal for adipose tissue engineering, ${ }^{41}$ but other studies have shown that $50-70 \mu \mathrm{m}$ mean pore size is required. ${ }^{42,43}$ Hence, there is a contradiction about pore properties for adipose tissue regeneration. To address this issue, we have measured 3D 


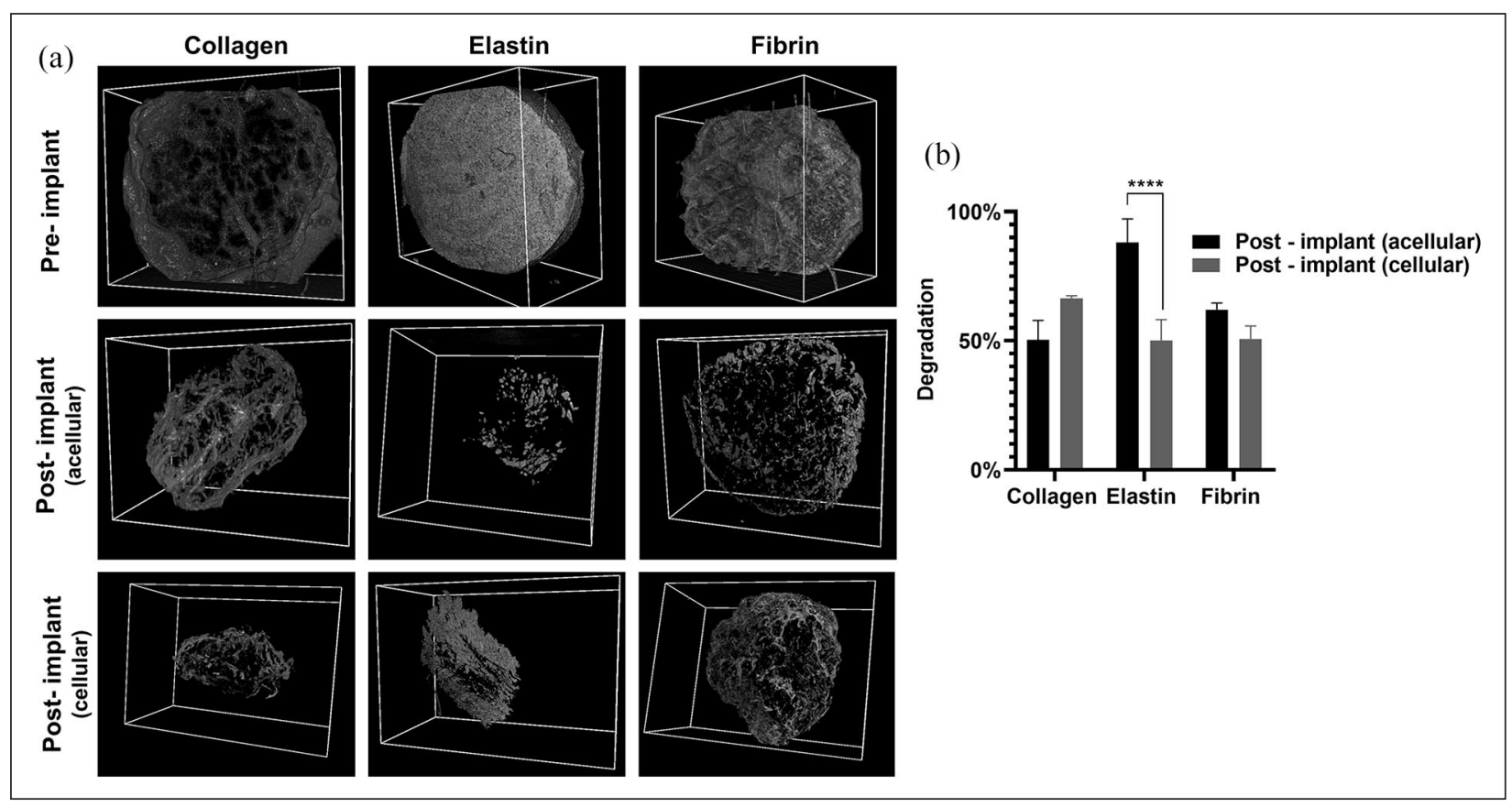

Figure 3. Pre-implanted 3D structure of the scaffold under $\mu C T$ and in vivo acellular and cellular degradation of the scaffolds after 28 days (a), and quantification of degradation (****p $<0.000 \mathrm{I})(\mathrm{b})$.

pore parameters in a pseudo-physiological environment mimicking the in vivo scenario by $\mu \mathrm{CT}$ as well as in $2 \mathrm{D}$ dry scaffolds using scanning electron microscopy (SEM) and analysed by Image $\mathrm{J}$ software. In 3D, all three scaffolds showed variation in the pore size and porosity (Figure 2(i) and (j)). Collagen had a porosity of $27.33 \%$, and $62 \%$ of pore diameter was between 17.93 and $35.86 \mu \mathrm{m}$; but in elastin, the majority $(41.33 \%)$ of pores were distributed in the $35.86-89.65 \mu \mathrm{m}$ range. Elastin was the most porous scaffold among three scaffolds with $79.19 \%$ of porosity. In the fibrin scaffold, pores were almost equally distributed in the range of $0-35.86 \mu \mathrm{m}$ and $35.86-89.65 \mu \mathrm{m}$ with total porosity of $43.28 \%$. Pore thickness for collagen and fibrin was mainly distributed in the range of $17.93-<35.86 \mu \mathrm{m}$ $(52.31 \%, 53.42 \%)$ and $35.86-89.65 \mu \mathrm{m}(36.92 \%, 40.76 \%)$ respectively. However, elastin had $86 \%$ of its pore thickness in the range of $17.93-<35.86 \mu \mathrm{m}$ (Figure $2(\mathrm{k})$ ). As per our findings, there was a discrepancy in the $2 \mathrm{D}$ (Supplemental Figure S1) and 3D (Figure 2(i)-(k)) pore properties. There are two reasons for this. Firstly, the difference in the method of analysis, such as using surface and volume-based techniques and secondly, modification in the swelling properties of scaffolds upon hydration as each scaffold has different swelling properties which alters the dynamics of the scaffolds such as porosity, pore thickness and pore range from the dry to a hydrated state. We would like to emphasise that the cellular activities such as proliferation, migration and attachment occur at the hydrated architecture of the scaffold rather than the dry state. Therefore, this fundamental difference in the analysis of scaffolds architecture is a key factor in understanding cell-material interaction in any biomaterial. Hence, it is advantageous to study pore properties in the hydrated and $3 \mathrm{D}$ state of the material.

\section{Biaxial mechanical properties}

In physiological conditions, tissues are under 3D forces. Hence to measure the mechanical properties of our scaffolds in vivo niche, we have created a pseudo-physiological environment using biaxial mechanical testing (longitudinal $(X)$ and transverse $(Y)$ axes). The tensile toughness of the material is the total energy density or energy per unit volume absorbed during deformation and is equal to the total area under the engineering stress-strain curve (Figure 4(a)). Hence, we have calculated the area under the hysteresis curve for both $X$ and $Y$ axes of the collagen, elastin and fibrin scaffolds. The collagen and fibrin scaffolds exhibited obvious hysteresis curves under the biaxial forces as they were able to form a fibrous architecture; therefore, they demonstrated the polymeric structure of the scaffolds. However, the elastin scaffold did not show proper hysteresis curve and exhibited differences in stiffness between $X$ and $Y$ axes which indicates a non-isotropic mechanical behaviour of the scaffold. This is most likely due to the geometry and porosity of the sample rather than its material. These finding could be correlated to the maximum force collagen $(X$ axis $=90.01 \pm 22.51 \mathrm{mN}$ and $Y$ axis $=94.00 \pm 6.08 \mathrm{mN})$, elastin $(X$ axis $=38.03 \pm 1.73 \mathrm{mN}$ and $Y$ axis $=32.33 \pm 6.42 \mathrm{mN})$, and fibrin $(X$ axis $=128.33 \pm$ $24.70 \mathrm{mN}$ and $Y$-axis $=105.05 \pm 17.69 \mathrm{mN}$ ) (Figure $4(\mathrm{~b})$ ) and the stress distribution across the scaffold (Figure 4(d)). 


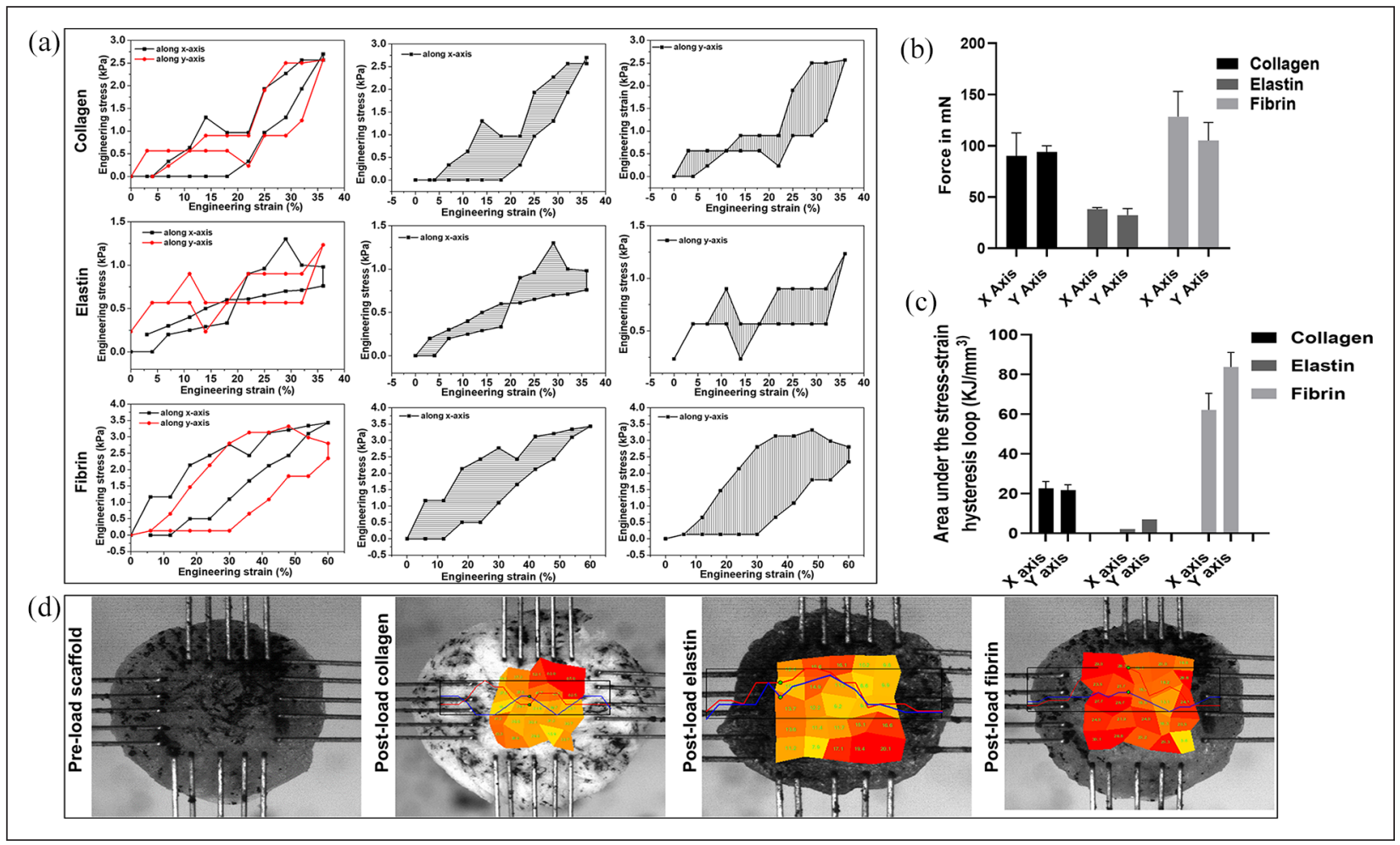

Figure 4. Mechanical properties of the scaffolds in a pseudo-physiological environment using biaxial mechanical testing longitudinal $(X)$ and transverse $(Y)$ axes: stress and strain curve (a), maximum force in $\mathrm{mN}(\mathrm{b})$, area under stress-strain hysteresis loop (c), and pre-loaded scaffold and stress distribution on the scaffold upon loading (d).

Moreover, the physical significance of the area within the stress-strain hysteresis loop is the energy absorbed during one loading-unloading cycle (Figure 4(c)). As per our findings, these mechanical parameters can be correlated to the structural and pore properties of the scaffolds.

\section{Cell viability and proliferation}

All three scaffolds showed continual proliferation and viability of human adipose-derived stem cells (hADSCs) (Figure 5). Cells in collagen showed elongated cell morphology at days 1 and 3, but at day 7, cells showed aggregated morphology and demonstrated the highest proliferative activity among all scaffolds. The hADSCs on the collagen scaffolds showed proliferative and aggregated morphology as collagen type 1 has a distant ligandbinding receptor for integrin $\alpha 1 \beta 1, \alpha 2 \beta 1$ and $\alpha 11 \beta 1$. Hence, hADSCs have a higher affinity for attachment and proliferation..$^{44,45}$ Role of fibrin gels on MSC proliferation and attachment has been successfully investigated for bone formation, intervertebral disc regeneration, differentiation potential and clinical studies of osteoarthritic knees in 17 patients. ${ }^{46-49}$ However, in our study hADSCs adhesion was poor and non-homogenously distributed but showed an increase in the absorbance and proliferation by day 7 from day 1 . This was because of the difference in the surface properties of the scaffold and method of cell seeding. In contrast, in elastin scaffolds, cells were homogeneously distributed on day 1 and demonstrated distinct spindle morphology with non-aggregated behaviour on days 3 and 7 with spindle-shaped morphology, and high proliferation compared to fibrin, although surface chemistry and properties of elastin were inferior to those of collagen and fibrin. ${ }^{50}$ This increase in the biological activity was because the elastin scaffold was the most porous and had a wide range in the pore sizes; hence the architectural property of the elastin scaffold played a vital role.

\section{Adipogenic differentiation}

Gene expression of two hADSCs markers OCT4 and REX1 and five lineage-specific differentiation markers (adipogenic differentiation markers CEBP and PPAR $\gamma$; myogenic marker MYOD1; osteogenic marker RUNX2 and chondrogenic marker SOX9) were evaluated after 3, 7 and 14 days of incubation of hADSC in collagen, elastin and fibrin scaffolds (Figure 6(e)). The main objective of this part of the study was to examine the differential ability of these three biomimetic scaffolds in the absence of external stimuli. Therefore, we have seeded these scaffolds and maintained them in stem cell proliferation media, and 


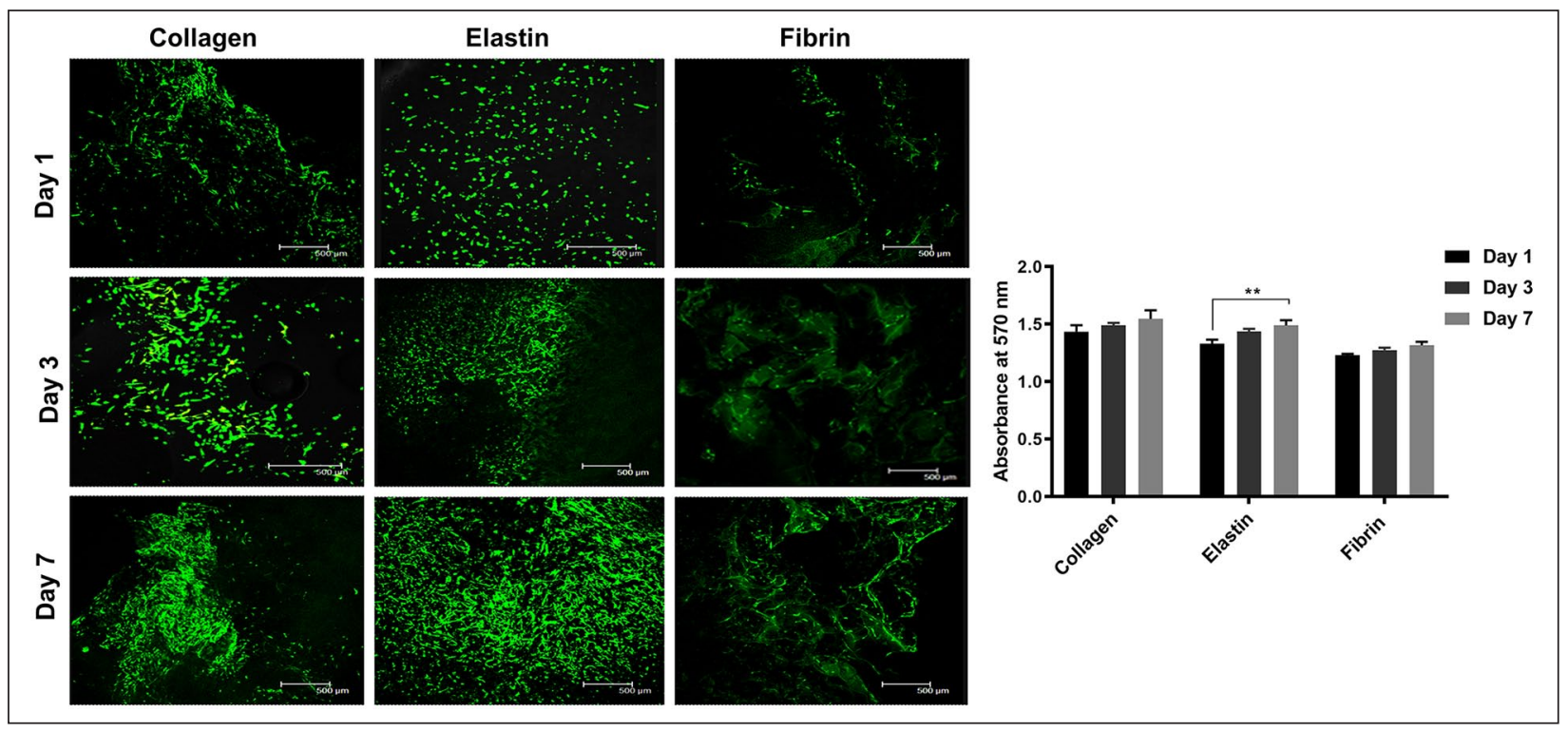

Figure 5. Live/dead assay and cellular behaviour on the scaffold for days I, 3 and 7 (a) and Alamar blue absorbance at $570 \mathrm{~nm}$ for days I, 3 and 7 (**denotes statistical significance of $p<0.0$ I from day I) (b).

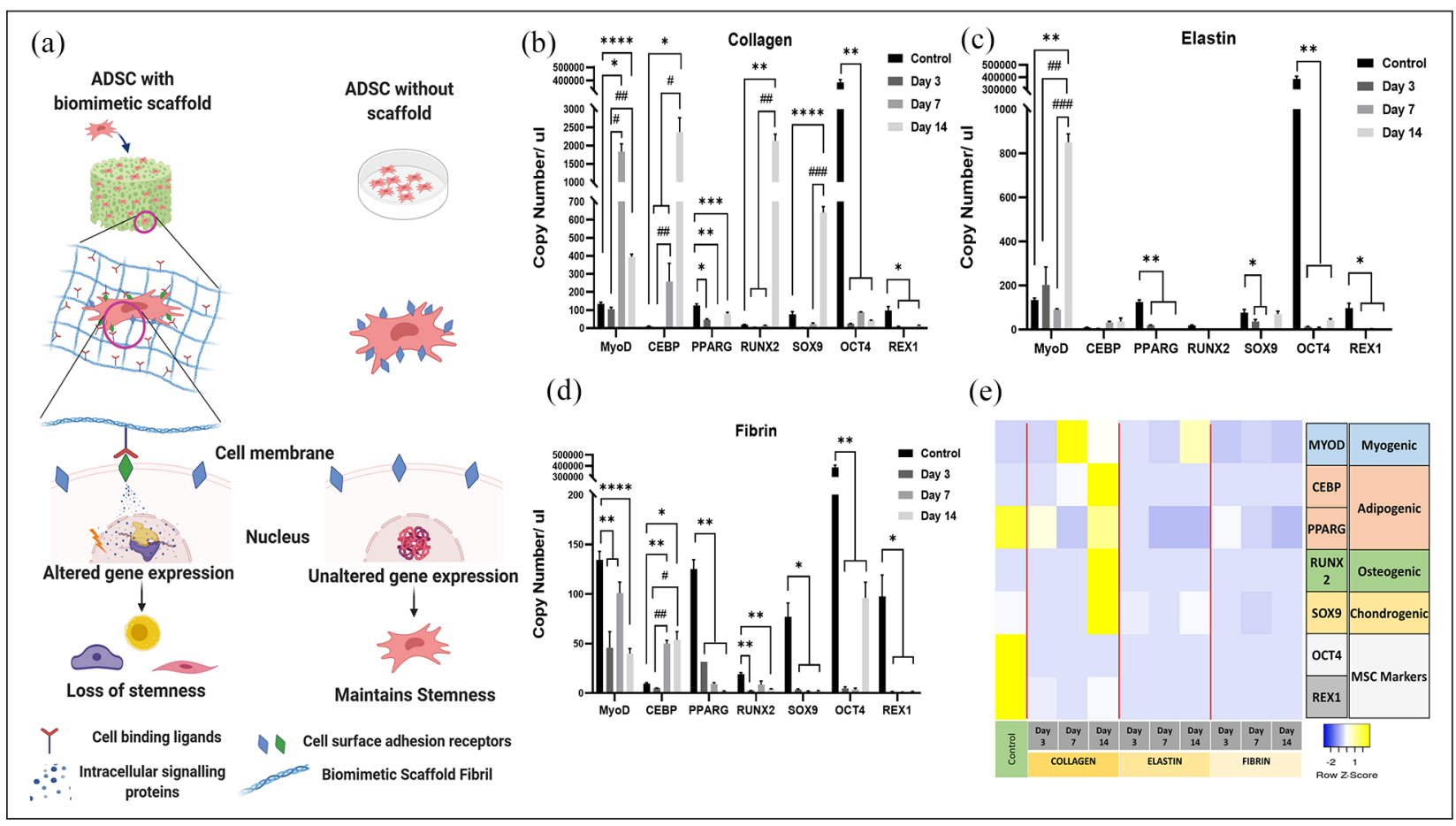

Figure 6. Schematic representation of ADSC behaviour with and without scaffold in a stem cell proliferation media without any external stimuli (a), q-PCR results for collagen (b), elastin (c), fibrin (d) $(* p<0.05$, $* * p<0.0$ I, and $* * * * p<0.000$ I to day I and

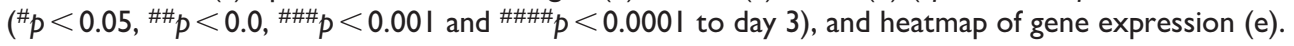

hADSCs cultured on tissue culture plastic has been used as baseline control (Figure 6(a)). GAPDH, the most common housekeeping gene and two others (B2M and PPIA) that were reported by Li et al. ${ }^{51}$ as the stable reference genes for mesenchymal stem cells were screened across the three scaffolds at all time points. The results displayed fluctuating $\mathrm{Ct}$ values across time points and scaffolds for all three housekeeping genes (Supplemental Figure S2), hence classing them unsuitable to be used as ideal reference points. The anomaly in gene expression of the same type of cells cultured on 2D and 3D surfaces explains this phenomenon..$^{52}$ There have been studies that have screened a range of housekeeping genes to identify the most suitable and stable reference for mesenchymal stem cells seeded on 
3D scaffolds. One such study demonstrated the stability of TATA-box protein (among 31 screened genes) to be used as a reference gene for bone marrow-derived mesenchymal stem cells. ${ }^{53}$ However, there is a contradictory report suggesting that it is the least suitable gene for mesenchymal stem cell monolayer culture. ${ }^{51}$ Due to the extensive range of genes that would have to be screened to identify the best-suited reference gene for each scaffold and the improbability of identifying a common gene that will render the three scaffolds comparable, makes this task infeasible. Hence the gene expression in hADSCs cultured in our biomimetic scaffolds has been expressed in terms of absolute copy number of mRNA extrapolated using the standard curve for each individual primer set. hADSCs cultured in all three scaffolds uniformly displayed a significant reduction of OCT4 $(p<0.01)$ and REX1 $(p<0.5)$ compared to control (ADSCs cultured on tissue culture plastic) at all time points. This implies that the ADSCs are losing their stemness as early as 3 days upon co-culture with these biomimetic scaffolds. Besides, the collagen matrix was observed to induce significant upregulation of late-stage adipogenic marker CEBP alpha by 250 -fold $(p<0.05)$ in comparison to control at day 14 (Figure 6(b)). A gradual upregulation of CEBP alpha was also observed in fibrin at day 7 and day $14(p<0.05)$ compared to control, although with much less intensity (5-fold increase) than ADSCs in a collagen matrix. However, PPAR $\gamma$, which plays a synergistic role with CEBP alpha in bringing about adipogenic differentiation, was observed to be downregulated significantly in all three scaffolds right from day 3 $(p<0.01)$. CEBP alpha and PPARG are key pro-adipogenic transcription factors that activate each other, thus triggering a positive feedback loop. They both, in turn, activate an array of adipogenic genes. ${ }^{54,55}$ The absence of PPAR $\gamma$ signifies that the ADSCs are not completely differentiated into adipocytes but suggests a possible inclination towards adipogenic lineage due to the increasing trend observed in CEBP alpha expression. The addition of external stimuli along with appropriate incubation time, might render a collagen and fibrin matrices more suitable for adipose tissue regeneration (Figure 6(d)). In vivo studies will throw more light upon the adipogenic differentiation potential of ADSC these biomimetic scaffolds. Myogenic differentiation marker MYOD1 showed a fluctuating expression trend in Collagen and Fibrin. In the collagen matrix, following a significant 13 -fold increase at day 7 , MYOD1 expression dropped to a three-fold increase compared to control at day 14. However, MYOD1 expression remained significantly higher than control $(p<0.05)$ at both day 7 and day 14. On the contrary, fibrin matrices displayed a significant reduction compared to control $(p<0.01)$ at all three-time points despite the fluctuating trend. Nevertheless, elastin exhibited a 6 -fold increase in expression compared to control at day $14(p<0.01)$. Interestingly, MYOD1 was the only differentiation marker that was selectively upregulated in elastin, while the other lineage markers reduced to negligible expression levels by day 14 (Figure 6(c)). This observation supports existing reports demonstrating the successful use of human elastinlike polypeptide scaffold (HELP) and silk-tropoelastin for myogenic differentiation. ${ }^{56-58}$ Dexamethasone is often used to induce osteogenic differentiation via RUNX2 activation..$^{59,60}$ However, there are several alternative induction protocols avoiding the use of dexamethasone and some methods solely using surface/3D matrix topography to induce osteogenic differentiation. ${ }^{61,62}$ Similarly, SOX9 is a crucial transcription factor that brings about chondrogenic differentiation through collagen II and aggrecan expression. ${ }^{63}$ Calabreze et al. ${ }^{64}$ demonstrated a significant increase in SOX9 expression after week 1 of culture in 3D collagen scaffold even in the absence of soluble factors, although their presence showed a substantially higher expression of SOX9. In line with this, the collagen matrix was also observed to exhibit significant upregulation of RUNX2 $(p<-0.01)$ and SOX9 $(p<0.0001)$ at day 14 compared to control. This observation correlates with several existing reports that have proved the suitability of type I collagen incorporated scaffolds for osteogenic ${ }^{65-67}$ and chondrogenic differentiation. ${ }^{64,68,69}$

\section{Angiogenesis}

Adipose tissue hypoxia is a root cause for chronic inflammation as diffusion of oxygen in tissue is limited up to 100-200 $\mu \mathrm{m}$ from the surface, and for gaseous exchange and nutrient transportation beyond that, an additional network of new blood vessels (angiogenesis) is required. Therefore, adipose tissue is highly vascularised. ${ }^{70,71}$ However, our scaffolds dimensions were larger than $200 \mu \mathrm{m}$ therefore, it was a prerequisite to understand the angiogenic potential of our scaffolds, and to do that we had injected a contrast agent in rats to visualise vascular network under $\mu \mathrm{CT}$ (Figure 7(a)). In collagen scaffolds presence of integrin receptor-like $\alpha 1 \beta 1, \alpha 2 \beta 1$ and $\alpha 11 \beta 1$ enhanced endothelial cell attachment and resulted in $15.37 \%$ vasculature in acellular scaffolds. However, in the cellular scaffolds, there was significantly higher vasculature because of increased levels of vascular endothelial growth factor (VEGF) and other cytokines in the presence of MSCs. ${ }^{72,73}$ There is evidence that elastin-derived peptides promote angiogenesis by upregulation of MT1-MMP, resulting in tubulogenesis and endothelial migration, ${ }^{74}$ but in our study elastin scaffolds were fabricated from an insoluble source, demonstrated hydrophobicity and high in vivo degradation, which resulted in poor vasculature in both acellular and cellular scaffolds. Fibrin scaffolds showed the highest vasculature (22\% acellular and 34\% cellular) (Figure 7(b)) because fibrin has a high affinity towards endothelial cell docking by the formation of focal adhesion complex that colocalises integrin, VEGF and fibroblast growth factor-2 (FGF-2) receptors and this cascade of growth factors promote angiogenesis. ${ }^{4,75-80}$ 


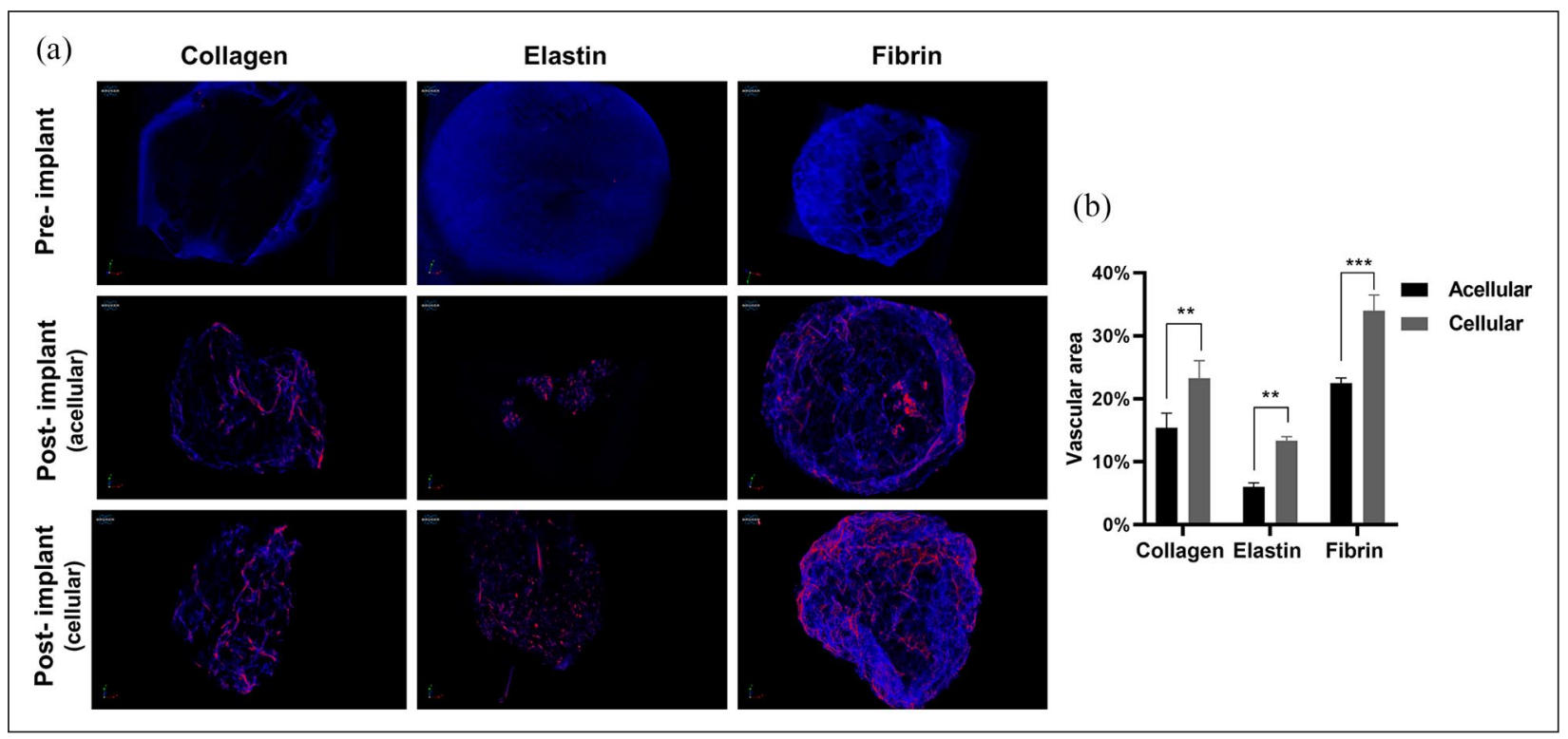

Figure 7. Pre-implanted 3D structure of the scaffold under $\mu \mathrm{CT}$ and angiogenesis (red colour) in vivo acellular and cellular scaffolds after 28 days (a), and quantification of angiogenesis (**p $<0.0 \mathrm{I}$, ***p $<0.00 \mathrm{I}$ ) (b).

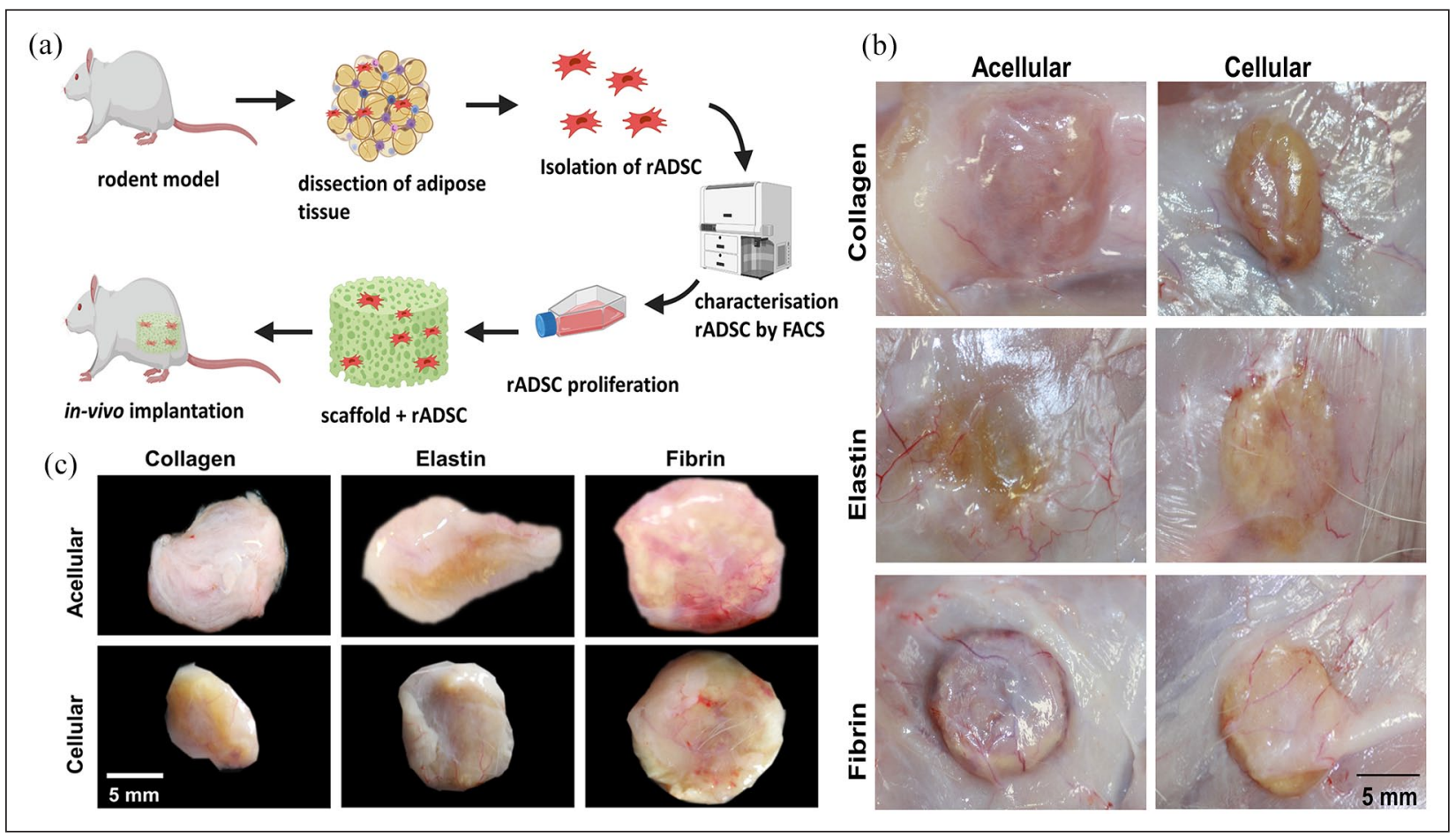

Figure 8. Schematic representation of isolation, characterisation and seeding of ADSCs on the scaffolds (a), in vivo integration and angiogenesis into scaffold after 28 days (b), and gross observation (c).

However, all scaffolds maintained their vascular homeostasis by capillary morphogenesis by day 28 .

\section{Adipose tissue regeneration}

The gross observation showed that all three scaffolds were able to integrate into the host tissue, and upon visual screening grafts were viable, and there was no evidence of superficial inflammatory reaction apart from fibrin (acellular and cellular) scaffolds (Figure 8(a)-(c)). Additionally, there was an invasion of blood vessels into all scaffolds. There was a good correlation between the amount of scaffold degradation after 28 days and uptake of the differential stain, but in collagen scaffolds uptake of Sirius Red 


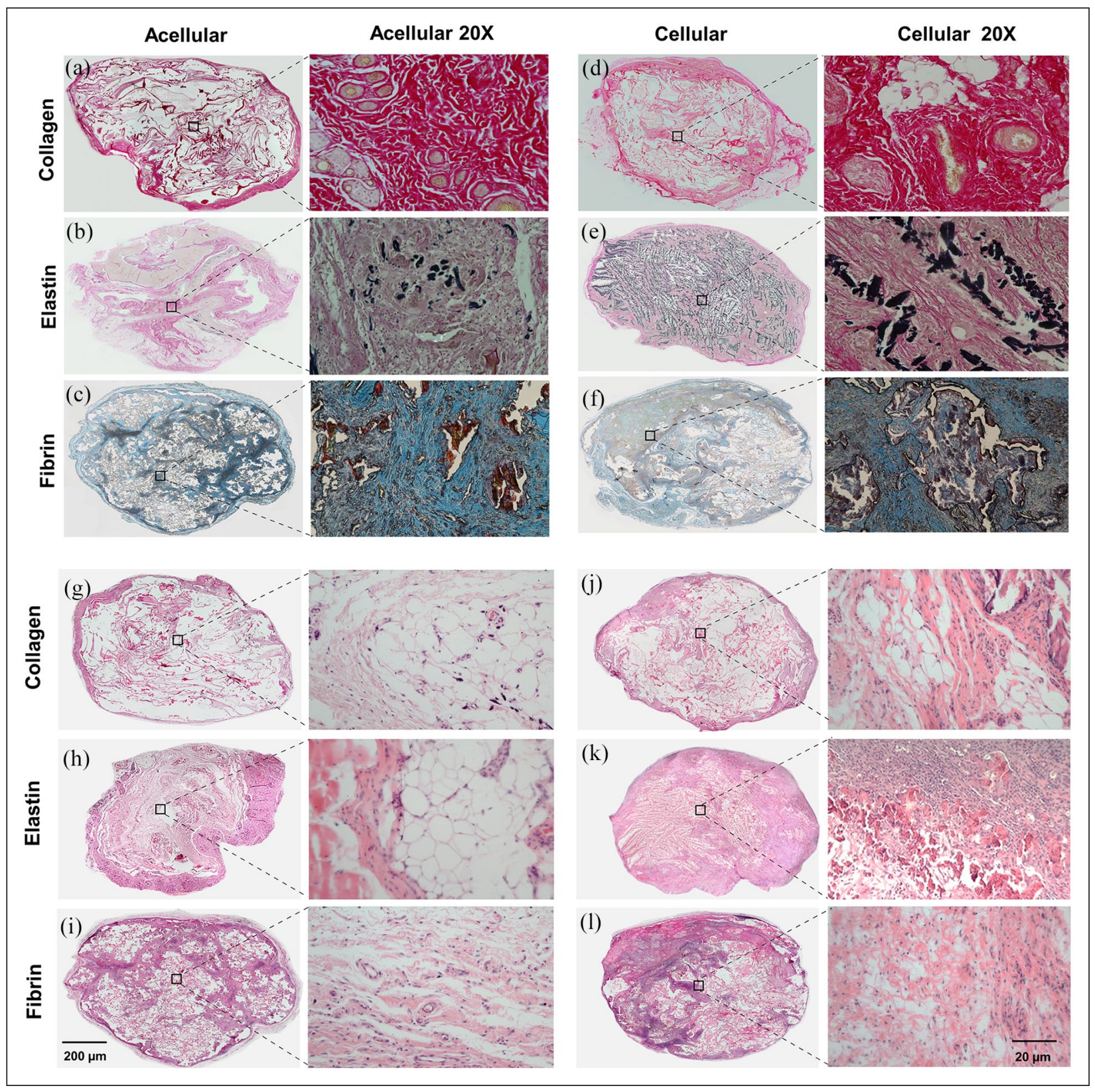

Figure 9. Differential stain for acellular and cellular scaffolds: Sirius Red stain for collagen (a) and (d), Verhoeff-Van Gieson stain (VVG) for elastin (b) and (e), Martius scarlet and blue (MSB) for fibrin (c) and (f), (h) and (e) staining for collagen (g) and (j), elastin (h) and (k), and fibrin (i) and (I).

was greater in an acellular group than the cellular group (Figure 9(a) and (d)). This phenomenon was not observed in elastin or fibrin scaffold groups. In the elastin cellular group, the remains of elastin scaffold (black) could be easily distinguished from the extracellular matrix stained in red/pink (Figure 9(b) vs (e)). However, in the acellular elastin group, since the scaffold was degraded the most, only a trace amount of elastin was present. In the acellular fibrin group, there was the presence of fibrin stained in brick red in the marginal amount, but in cellular group presence of brick red colour was predominant with conventional fibre boundaries (Figure 9(c) and (f)). The $\mathrm{H}$ and $\mathrm{E}$ evaluation showed by 28 days cell infiltration and attachment in the acellular scaffolds and proliferating cells in cellular scaffolds. Collagen and elastin scaffolds elicited a marginal immune response in the both acellular and cellular group (Figure $9(\mathrm{~g})-(\mathrm{j})$ and $(\mathrm{h})-(\mathrm{k})$ ), but the fibrin scaffold showed more cellularity and a significant amount of immune response (Figure 9(i) and (1)). We have observed more inflammation in the fibrin scaffold because fibrin enhances inflammatory response by leucocyte migration and endothelial cells by the influx of cytokines such as 


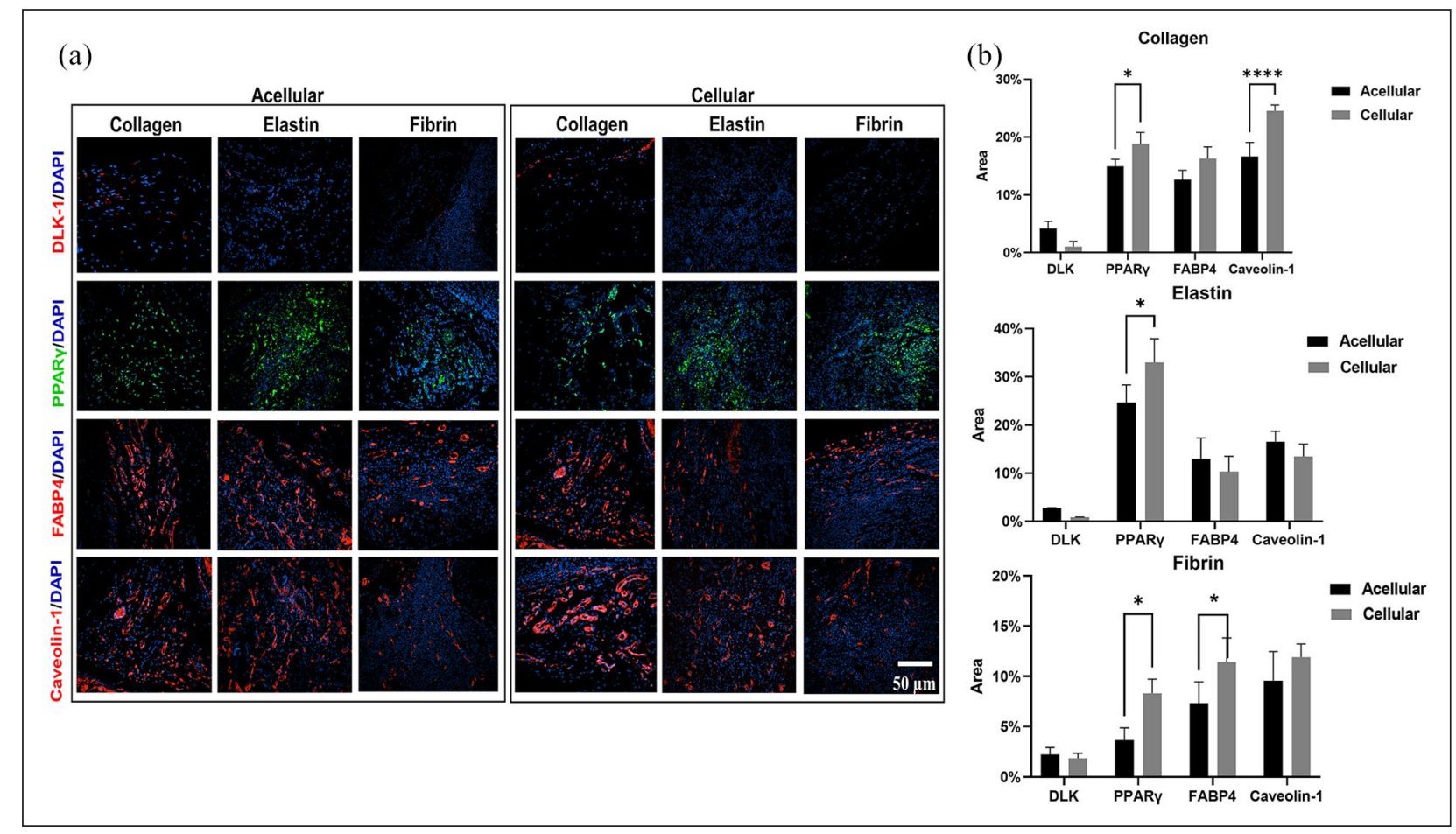

Figure 10. Immunofluorescence staining for collagen, elastin and fibrin scaffold in the acellular and cellular group using DLK-I, PPAR $\gamma$, FABP4 and Caveolin-I antibodies (a), and quantification data of the immunofluorescence staining for collagen, elastin and fibrin (b).

TNF, IL-1 and IL $6 .{ }^{81}$ In this study adipogenesis in scaffolds was analysed at four levels using immunofluorescence: (1) Adipogenesis reduction usingDLK-1, an adipogenesis inhibitor, (2) Adipogenesis at the gene expression level by PPAR $\gamma$, an adipogenic transcriptional factor, (3) Adipogenesis at the cytoplasmic level by FABP4, a cytoplasmic lipid transport protein, and (4) Adipogenesis at cell plasma level by Caveolin-1 an adipocyte cell membrane protein (Figure 10(a)). DLK-1 activates a cascade of MAPK/ERK pathways by upregulating SOX-9 expression, which inhibits adipogenesis and acts as a gatekeeper in adipogenesis. ${ }^{76,77}$ In our study, the expression of DLK-1 was marginal in all scaffolds, which indicates that the material properties of scaffolds did not arrest adipogenesis. Interestingly, in cellular groups absence of DLK-1 expression, a positive control for ADSC, indicated that seeded ADSCs lost their stemness and differentiated. ${ }^{76}$ All scaffolds showed a varied expression of PPAR $\gamma$, which is a nuclear receptor that forms a heterodimer with retinoid $\mathrm{X}$ receptors, regulates adipogenesis at the transactional level and has a pivotal role in lipid metabolism. Real-time PCR result reported that the collagen type 1 scaffolds upregulate PPAR $\gamma$ gene expression in vivo, ${ }^{82}$ but in our scaffolds, immuno-histological expression of PPAR $\gamma$ was weaker, as cellularity in collagen scaffolds was minimal. The expression of fatty acid chaperone FABP4 for all scaffolds was corresponding to the expression of PPAR $\gamma$ as FABP4 is induced by PPAR $\gamma .{ }^{83-85}$ In collagen scaffolds, the expression of FABP4 and Caveolin-1, which is expressed in mature adipocytes was the highest. Elastinbased scaffolds showed the highest expression of PPAR $\gamma$ as elastin was most the degraded scaffold, and degraded elastin fragments upregulate PPAR $\gamma^{86}$ hence, resulted in higher expression FABP4 and Caveolin-1 in acellular elastin scaffolds. However, in cellular elastin scaffold, the degradation was less; hence the expression of PPAR $\gamma$, FABP4 and Caveolin-1 was lower than in cellular elastin. In fibrin scaffolds expression of PPAR $\gamma$, FABP4 and Caveolin-1 were marginal in the acellular group, although in fibrin glue with hADSC had shown excellent adipogenicity in vivo. ${ }^{87}$ In our experiments, we have used crosslinked and lyophilised fibrin scaffold, which has demonstrated weak cell-material interaction. Therefore, the results indicated that scaffolds seeded with ADSC enhance adipogenesis (Figure 10(b)).

\section{Conclusion}

In this study, we have successfully elucidated biomimetic cues by physical and biological characterisation in vitro mimicking physiological conditions and in vivo rodent model. Hence, we can conclude that the 3D geometry of scaffolds fabricated from natural polymers present in the human ECM with ADSCs provides environmental clues for adipogenesis. All these scaffolds possess different physical and structural properties, and upon seeding with 
ADSCs without any external stimuli these ADSCs sense topology of scaffolds and lost their stemness and demonstrated differentiation potential into various mesenchymal lineages. We have successfully calculated 3D mechanical, structural and pore properties corresponding to in vivo physiological state. All these findings suggested that each of these natural polymers have a pivotal role in adipose tissue engineering like collagen is ideal for cellular activities and adipogenesis. Elastin contributed to adipogenesis by maintaining the balance between scaffold degradation and endogenous neo-tissue formation, and fibrin is an excellent promoter of angiogenesis. This study has advanced our understanding of cell-material interaction and the role of these ECM polymers in soft tissue regeneration.

\section{Declaration of conflicting interests}

The author(s) declared no potential conflicts of interest with respect to the research, authorship, and/or publication of this article.

\section{Funding}

The author(s) disclosed receipt of the following financial support for the research, authorship, and/or publication of this article: This work was supported by the Restoration of Appearance and Function Trust (UK Registered Charity No 299811) and the National Research Foundation (NRF) of Republic of Korea (Global Research Lab Program 2015-0093829, Global Research Development Center Program 2018R1D1A1B07048020, 2018K1A4A3A01064257, and 2017R1C1B1011387).

\section{ORCID iDs}

Prasad Sawadkar (iD https://orcid.org/0000-0003-2956-1592

Jung- Hwan Lee (iD https://orcid.org/0000-0001-8678-5459

Hae-Won Kim (iD https://orcid.org/0000-0001-6400-6100

Jonathan Knowles iD https://orcid.org/0000-0003-3917-3446

\section{Supplemental material}

Supplemental material for this article is available online.

\section{References}

1. Mahoney CM, Imbarlina C, Yates CC, et al. Current therapeutic strategies for adipose tissue defects/repair using engineered biomaterials and biomolecule formulations. Front Pharmacol 2018; 9: 507.

2. O'Brien FJ. Biomaterials \& scaffolds for tissue engineering. Mater Today 2011; 14: 88-95.

3. Neuber F. Fettransplantation. Chir Kongr Verhandl Dsch Gesellch Chir 1893; 22: 66.

4. Sell SA, Wolfe PS, Garg K, et al. The use of natural polymers in tissue engineering: a focus on electrospun extracellular matrix analogues. Polymers 2010; 2: 522-553.

5. Zhang $\mathrm{N}$ and Kohn DH. Using polymeric materials to control stem cell behavior for tissue regeneration. Birth Defects Res Part C, Embryo Today Rev 2012; 96: 63-81.
6. Daamen WF, Veerkamp JH, van Hest JCM, et al. Elastin as a biomaterial for tissue engineering. Biomaterials 2007; 28: 4378-4398.

7. Buttafoco L, Kolkman NG, Engbers-Buijtenhuijs P, et al. Electrospinning of collagen and elastin for tissue engineering applications. Biomaterials 2006; 27: 724-734.

8. Harkness RD. Biological functions of collagen. Biol Rev 1961; 36: 399-455.

9. Lee $\mathrm{CH}$, Singla A and Lee Y. Biomedical applications of collagen. Int J Pharm 2001; 221: 1-22.

10. Sawadkar P, Sibbons P, Ahmed T, et al. Engineering of a functional tendon using collagen as a natural polymer. ACS Biomater Sci Eng 2019; 5: 5218-5228.

11. Zhao M, Anouz R and Groth T. Effect of microenvironment on adhesion and differentiation of murine $\mathrm{C} 3 \mathrm{H} 10 \mathrm{~T} 1 / 2$ cells cultured on multilayers containing collagen I and glycosaminoglycans. J Tissue Eng 2020; 11: 2041731420940560.

12. Mithieux SM and Weiss AS. Elastin. Adv Protein Chem 2005; 70: 437-461.

13. Petersen E, Wagberg F and Angquist KA. Serum concentrations of elastin-derived peptides in patients with specific manifestations of atherosclerotic disease. Eur J Vasc Endovasc Surg 2002; 24: 440-444.

14. Doolittle RF. Fibrinogen and fibrin. Annu Rev Biochem 1984; 53: 195-229.

15. Jain S, Yassin MA, Fuoco T, et al. Engineering 3D degradable, pliable scaffolds toward adipose tissue regeneration; optimized printability, simulations and surface modification. J Tissue Eng 2020; 11: 2041731420954316.

16. Prasadh S and Wong RCW. Unraveling the mechanical strength of biomaterials used as a bone scaffold in oral and maxillofacial defects. Oral Sci Int 2018; 15: 48-55.

17. Han S, Sun HM, Hwang KC, et al. Adipose-derived stromal vascular fraction cells: update on clinical utility and efficacy. Crit Rev Eukaryot Gene Expr 2015; 25: 145-152.

18. Tsuji W, Rubin JP and Marra KG. Adipose-derived stem cells: implications in tissue regeneration. World J Stem Cells 2014; 6: 312-321.

19. Mitchell JB, McIntosh K, Zvonic S, et al. Immunophenotype of human adipose-derived cells: temporal changes in stromal-associated and stem cell-associated markers. Stem Cells (Dayton, Ohio) 2006; 24: 376-385.

20. Zhu W and Nelson CM. Adipose and mammary epithelial tissue engineering. Biomatter 2013; 3: e24630.

21. Augello A and De Bari C. The regulation of differentiation in mesenchymal stem cells. Hum Gene Therapy 2010; 21: 1226-1238.

22. Eke G, Mangir N, Hasirci N, et al. Development of a UV crosslinked biodegradable hydrogel containing adipose derived stem cells to promote vascularization for skin wounds and tissue engineering. Biomaterials 2017; 129: 188-198.

23. Sawadkar P, Mohanakrishnan J, Rajasekar P, et al. A synergistic relationship between polycaprolactone and natural polymers enhances the physical properties and biological activity of scaffolds. ACS Appl Mater Interfaces 2020; 12: 13587-13597.

24. Kristensen JH, Karsdal MA. Chapter 30 - Elastin. In: MA Karsdal (ed.) Biochemistry of collagens, laminins and elastin. Cambridge, MA: Academic Press, 2016, pp.197-201. 
25. van Oss CJ. Surface properties of fibrinogen and fibrin. $J$ Protein Chem 1990; 9: 487-491.

26. Liu C, Shen SZ and Han Z. Surface wettability and chemistry of ozone perfusion processed porous collagen scaffold. $J$ Bionic Eng 2011; 8: 223-233.

27. de Campos Vidal B and Mello MLS. Collagen type I amide I band infrared spectroscopy. Micron 2011; 42: 283-289.

28. Belbachir K, Noreen R, Gouspillou G, et al. Collagen types analysis and differentiation by FTIR spectroscopy. Anal Bioanal Chem 2009; 395: 829-837.

29. Petibois C, Gouspillou G, Wehbe K, et al. Analysis of type I and IV collagens by FT-IR spectroscopy and imaging for a molecular investigation of skeletal muscle connective tissue. Anal Bioanal Chem 2006; 386: 1961-1966.

30. Riaz T, Zeeshan R, Zarif F, et al. FTIR analysis of natural and synthetic collagen. Appl Spectrosc Rev 2018; 53: 703-746.

31. Jonak R, Nemetschek-Gansler H, Nemetschek T, et al. Glutaraldehyde-induced states of stress of the collagen triple helix. J Mol Biol 1979; 130: 511-512.

32. Terzi A, Storelli E, Bettini S, et al. Effects of processing on structural, mechanical and biological properties of collagenbased substrates for regenerative medicine. Scientific Rep 2018; 8: 1429.

33. Olde Damink LHH, Dijkstra PJ, Van Luyn MJA, et al. Glutaraldehyde as a crosslinking agent for collagen-based biomaterials. J Mater Sci Mater Med 1995; 6: 460-472.

34. Vasconcelos A, Gomes AC and Cavaco-Paulo A. Novel silk fibroin/elastin wound dressings. Acta Biomater 2012; 8: 3049-3060.

35. Popescu MC, Vasile C and Craciunescu O. Structural analysis of some soluble elastins by means of FT-IR and 2D IR correlation spectroscopy. Biopolymers 2010; 93: 10721084.

36. Bramanti E, Benedetti E, Sagripanti A, et al. Determination of secondary structure of normal fibrin from human peripheral blood. Biopolymers 1997; 41: 545-553.

37. Montalbano G, Toumpaniari S, Popov A, et al. Synthesis of bioinspired collagen/alginate/fibrin based hydrogels for soft tissue engineering. Mater Sci Eng C 2018; 91: 236-246.

38. Grover $\mathrm{CN}$, Cameron RE and Best SM. Investigating the morphological, mechanical and degradation properties of scaffolds comprising collagen, gelatin and elastin for use in soft tissue engineering. J Mech Behav Biomed Mater 2012; 10: 62-74.

39. Petersen A, Joly P, Bergmann C, et al. The impact of substrate stiffness and mechanical loading on fibroblastinduced scaffold remodeling. Tissue Eng Part A 2012; 18: 1804-1817.

40. Klumpers DD, Zhao X, Mooney DJ, et al. Cell mediated contraction in $3 \mathrm{D}$ cell-matrix constructs leads to spatially regulated osteogenic differentiation. Integr Biol (Camb) 2013; 5: 1174-1183.

41. Tytgat L, Kollert MR, Van Damme L, et al. Evaluation of 3D printed gelatin-based scaffolds with varying pore size for MSC-based adipose tissue engineering. Macromol Biosci 2020; 20: 1900364.

42. Guneta V, Loh QL and Choong C. Cell-secreted extracellular matrix formation and differentiation of adipose-derived stem cells in 3D alginate scaffolds with tunable properties. $J$ Biomed Mater Res A 2016; 104: 1090-1101.
43. Kral JG and Crandall DL. Development of a human adipocyte synthetic polymer scaffold. Plast Reconstr Surg 1999; 104: 1732-1738.

44. Heino J. The collagen receptor integrins have distinct ligand recognition and signaling functions. Matrix Biol J Int Soc Matrix Biol 2000; 19: 319-323.

45. Popov C, Radic T, Haasters F, et al. Integrins alpha2beta 1 and alpha11betal regulate the survival of mesenchymal stem cells on collagen I. Cell Death Dis 2011; 2: e186.

46. Yamada Y, Seong Boo J, Ozawa R, et al. Bone regeneration following injection of mesenchymal stem cells and fibrin glue with a biodegradable scaffold. J Cranio-Maxillofac Surg 2003; 31: 27-33.

47. Gasparotto VPO, Landim-Alvarenga FC, Oliveira ALR, et al. A new fibrin sealant as a three-dimensional scaffold candidate for mesenchymal stem cells. Stem Cell Res Therapy 2014; 5: 78.

48. Tang X, Ouyang A, Liebenberg E, et al. 3D fibrin gels direct extracellular matrix production in intervertebral disc cells under hypoxic conditions. Global Spine J 2014; 4. DOI: 10.1055/s-0034-1376646.

49. Sheykhhasan M, Qomi RT and Ghiasi M. Fibrin scaffolds designing in order to human adipose-derived mesenchymal stem cells differentiation to chondrocytes in the presence of TGF- $\beta 3$. Int J Stem Cells 2015; 8: 219-227.

50. Zhang Z, Ortiz O, Goyal R, et al. 13 - Biodegradable polymers. In: Modjarrad K and Ebnesajjad S (eds) Handbook of polymer applications in medicine and medical devices. Oxford: William Andrew Publishing, 2014, pp.303-335.

51. Li X, Yang Q, Bai J, et al. Identification of appropriate reference genes for human mesenchymal stem cell analysis by quantitative real-time PCR. Biotechnol Lett 2015; 37: 67-73.

52. Frith JE, Thomson B and Genever PG. Dynamic threedimensional culture methods enhance mesenchymal stem cell properties and increase therapeutic potential. Tissue Eng Part C Methods 2010; 16: 735-749.

53. Rauh J, Jacobi A and Stiehler M. Identification of stable reference genes for gene expression analysis of threedimensional cultivated human bone marrow-derived mesenchymal stromal cells for bone tissue engineering. Tissue Eng Part C Methods 2015; 21: 192-206.

54. Lefterova MI, Zhang Y, Steger DJ, et al. PPAR $\gamma$ and C/EBP factors orchestrate adipocyte biology via adjacent binding on a genome-wide scale. Genes Dev 2008; 22: 2941-2952.

55. Lowe CE, O'Rahilly S and Rochford JJ. Adipogenesis at a glance. J Cell Sci 2011; 124: 2681-2686.

56. D'Andrea P, Civita D, Cok M, et al. Myoblast adhesion, proliferation and differentiation on human elastin-like polypeptide (HELP) hydrogels. J Appl Biomater Funct Mater 2017; 15(1): e43-e53.

57. D'Andrea P, Scaini D, Severino LU, et al. In vitro myogenesis induced by human recombinant elastin-like proteins. Biomaterials 2015; 67: 240-253.

58. Hu X, Park SH, Gil ES, et al. The influence of elasticity and surface roughness on myogenic and osteogenic-differentiation of cells on silk-elastin biomaterials. Biomaterials 2011; 32: 8979-8989.

59. Hamidouche Z, Hay E, Vaudin P, et al. FHL2 mediates dexamethasone-induced mesenchymal cell differentiation 
into osteoblasts by activating Wnt/beta-catenin signalingdependent Runx2 expression. Faseb J 2008; 22: 3813-3822.

60. Vater C, Kasten P and Stiehler M. Culture media for the differentiation of mesenchymal stromal cells. Acta Biomater 2011; 7: 463-477.

61. Kroeze RJ, Knippenberg M and Helder MN. Osteogenic differentiation strategies for adipose-derived mesenchymal stem cells. In: Gimble JM and Bunnell BA (eds) Adiposederived stem cells: methods and protocols. Vol. 702. New York, NY: Humana Press, 2011, pp.233-248.

62. Faia-Torres $\mathrm{AB}$, Charnley M, Goren $\mathrm{T}$, et al. Osteogenic differentiation of human mesenchymal stem cells in the absence of osteogenic supplements: a surface-roughness gradient study. Acta Biomater 2015; 28: 64-75.

63. Bi W, Deng JM, Zhang Z, et al. Sox9 is required for cartilage formation. Nat Genet 1999; 22: 85-89.

64. Calabrese G, Forte S, Gulino R, et al. Combination of collagen-based scaffold and bioactive factors induces adipose-derived mesenchymal stem cells chondrogenic differentiation in vitro. Front Physiol 2017; 8: 50.

65. Mazzoni E, D'Agostino A, Iaquinta MR, et al. Hydroxylapatite-collagen hybrid scaffold induces human adipose-derived mesenchymal stem cells to osteogenic differentiation in vitro and bone regrowth in patients. Stem Cells Transl Med 2020; 9: 377-388.

66. Assaf RB, Fayyad-Kazan M, Al-Nemer F, et al. Evaluation of the osteogenic potential of different scaffolds embedded with human stem cells originated from schneiderian membrane: an in vitro study. Biomed Res Int 2019; 2019: 2868673.

67. Hanna H, Mir LM and Andre FM. In vitro osteoblastic differentiation of mesenchymal stem cells generates cell layers with distinct properties. Stem Cell ResTherapy 2018; 9: 1025.

68. Meng F, Zhang Z, Huang G, et al. Chondrogenesis of mesenchymal stem cells in a novel hyaluronate-collagen-tricalcium phosphate scaffolds for knee repair. Eur Cell Mater 2016; 31: 79-94.

69. Noth U, Rackwitz L, Heymer A, et al. Chondrogenic differentiation of human mesenchymal stem cells in collagen type I hydrogels. J Biomed Mater Res Part A 2007; 83A: 626-635.

70. Carmeliet $P$ and Jain RK. Angiogenesis in cancer and other diseases. Nature 2000; 407: 249-257.

71. Ye J. Adipose tissue vascularization: its role in chronic inflammation. Curr Diabetes Rep 2011; 11: 203-210.

72. Twardowski T, Fertala A, Orgel JP, et al. Type I collagen and collagen mimetics as angiogenesis promoting superpolymers. Curr Pharm Des 2007; 13: 3608-3621.

73. Rustad KC, Wong VW, Sorkin M, et al. Enhancement of mesenchymal stem cell angiogenic capacity and stemness by a biomimetic hydrogel scaffold. Biomaterials 2012; 33: 80-90.

74. Altankov G, Grinnell F and Groth T. Studies on the biocompatibility of materials: fibroblast reorganization of substratum-bound fibronectin on surfaces varying in wettability. $J$ Biomed Mater Res 1996; 30: 385-391.

75. Mosesson MW. Fibrinogen and fibrin structure and functions. 2005; 3: 1894-1904.

76. Rybarczyk BJ, Lawrence SO and Simpson-Haidaris PJ. Matrix-fibrinogen enhances wound closure by increasing both cell proliferation and migration. Blood 2003; 102: 4035-4043.

77. Drew AF, Liu H, Davidson JM, et al. Wound-healing defects in mice lacking fibrinogen. Blood 2001; 97: 3691-3698.

78. Mosesson MW, Siebenlist KR and Meh DA. The structure and biological features of fibrinogen and fibrin. Ann NY Acad Sci 2001; 936: 11-30.

79. Sahni A and Francis CW. Vascular endothelial growth factor binds to fibrinogen and fibrin and stimulates endothelial cell proliferation. Blood 2000; 96: 3772-3778.

80. Takahashi N, Seko Y, Noiri E, et al. Vascular endothelial growth factor induces activation and subcellular translocation of focal adhesion kinase (p125FAK) in cultured rat cardiac myocytes. Circ Res 1999; 84: 1194-1202.

81. Jensen T, Kierulf P, Sandset PM, et al. Fibrinogen and fibrin induce synthesis of proinflammatory cytokines from isolated peripheral blood mononuclear cells. Thromb Haemost 2007; 97: 822-829.

82. Itoi $\mathrm{Y}$, Takatori $\mathrm{M}$, Hyakusoku $\mathrm{H}$, et al. Comparison of readily available scaffolds for adipose tissue engineering using adipose-derived stem cells. J Plast Reconstr Aesthet Surg 2010; 63: 858-864.

83. Furuhashi M and Hotamisligil GS. Fatty acid-binding proteins: role in metabolic diseases and potential as drug targets. Nat Rev Drug Discov 2008; 7: 489-503.

84. Boord JB, Fazio S and Linton MF. Cytoplasmic fatty acidbinding proteins: emerging roles in metabolism and atherosclerosis. Curr Opin Lipidol 2002; 13: 141-147.

85. Garin-Shkolnik T, Rudich A, Hotamisligil GS, et al. FABP4 attenuates PPAR $\gamma$ and adipogenesis and is inversely correlated with PPAR $\gamma$ in adipose tissues. Diabetes 2014; 63: 900 .

86. Tai HC, Tsai PJ, Chen JY, et al. Peroxisome proliferatoractivated receptor gamma level contributes to structural integrity and component production of elastic fibers in the Aorta. Hypertension 2016; 67: 1298-1308.

87. Verseijden F, Posthumus-van Sluijs SJ, van Neck JW, et al. Comparing scaffold-free and fibrin-based adipose-derived stromal cell constructs for adipose tissue engineering: an in vitro and in vivo study. Cell Transpl 2012; 21: 2283-2297. 